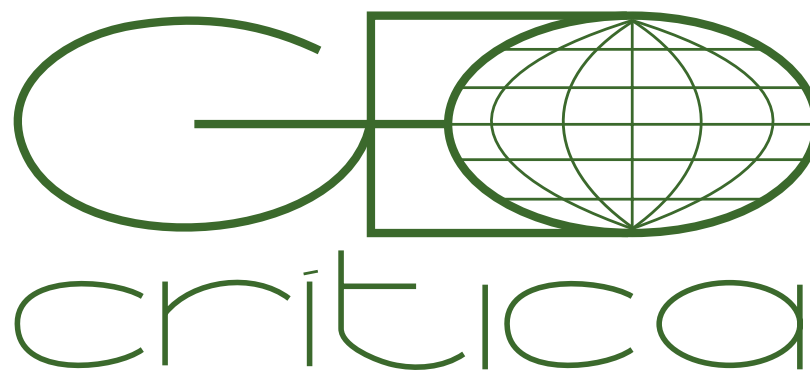

\section{Scripta Nova}

Revista Electrónica de Geografía y Ciencias Sociales Universitat de Barcelona

15 de octubre de 2017

\title{
LOS CINCO BELCHITES. UTOPÍAS Y HETEROTOPÍAS EN EL PRIMER FRANQUISMO
}

\author{
Carlos Bitrián Varea \\ Universitat Politècnica de Catalunya \\ carlos.bitrian@upc.edu
}

Recibido: 25 de abril de 2017. Devuelto para correcciones: 7 de junio de 2017. Aceptado: 6 de agosto de 2017.

Este trabajo se enmarca en la investigación doctoral que desarrollo bajo la dirección de la profesora Marta Llorente sobre los pueblos destruidos durante la Guerra Civil Española y conservados en ruinas en la actualidad. Expuse las líneas básicas de este estudio en una conferencia organizada por el ayuntamiento de Belchite y celebrada en el pueblo nuevo el 30 de agosto de 2014.
Resumen. Los cinco Belchites. Utopías y heterotopías en el primer franquismo El presente artículo analiza una de las operaciones espaciales de tipo simbólico más importantes de las emprendidas por el primer franquismo, la de la creación de una ciudad dual, Belchite, donde pudiera experimentarse a través de los sentidos el relato político en el que los sublevados pretendían basar el golpe militar de 1936, la guerra civil y el régimen subsiguiente. Este trabajo contrasta la utopía urbana que pretendió construirse a través del símbolo de los dos Belchites (el de la modernización y el de las ruinas) con la existencia de tres Belchites más. Porque cuando el símbolo se acuñó, en la localidad no había solo dos núcleos habitados sino cinco (uno de ellos en construcción), de los cuales tres eran espacios disciplinarios fruto de una represión de diferente intensidad. Mediante un caso paradigmático de alto contenido simbólico, este estudio pretende plantear la vertiente espacial de la violencia del régimen y la existencia de diferentes tipos de heterotopías franquistas.

Palabras clave: Franquismo, Belchite, represión espacial, reconstrucción, políticas de memoria.

\section{Abstract. The five Belchites. Utopias and heterotopias at the first Francoist \\ Spain}

The present work analyses one of the most important spatial operations of symbolic nature of those undertaken by the first Francoism: the creation of a dual city, Belchite, where it were possible to experience through the senses the political discourse on which the rebels intended to base the military coup of 1936, the civil war and the subsequent regime. This work contrasts the urban utopia that the regime tried to build through the symbol of "the two Belchite" (the modern one and that of the ruins) with the existence of three more Belchite. Because, when the symbol was coined, in the village there were not only two inhabited areas but five (one of them under construction), of which three were disciplinary spaces that were the result of a repression of varying intensity. Through a paradigmatic case with high symbolic content, this study intend to raise the question of the spatial dimension of the regime's violence, and the existence of different types of Francoist heterotopias.

Key words: Francoist Spain, Belchite, spatial repression, reconstruction, politics of memory. 
Es objeto del presente artículo analizar una de las operaciones de más alto contenido simbólico llevadas a cabo por el primer franquismo en la creación de un espacio ejemplar para el nuevo régimen. Esa operación, consistente en la conversión de Belchite en una suerte de utopía falangista ${ }^{1}$ mediante la que se pudiese confrontar sensorialmente el nuevo Estado con la "antiespaña" republicana, supuso la creación de diversos "espacios otros" que apenas han recibido atención y que planteamos aquí como ejemplos paradigmáticos de los espacios heterotópicos del primer franquismo, todavía desconocidos en muchos aspectos. El Belchite actual, fruto de la materialización del "símbolo de los dos Belchites" no puede entenderse, como pretendemos mostrar, sin los otros tres Belchites que, aun siendo esenciales para su construcción, quedaron al margen de la narrativa franquista. Incorporarlos a la memoria colectiva puede servir para ayudar a afrontar los actuales problemas de conservación del pueblo.

La reconstrucción urbana, que adquirió considerable importancia en el relato simbólico del régimen, tuvo que conciliar dos tendencias entonces presentes: la voluntad de modernización de la ciudad y de la vivienda ${ }^{2}$ y el aprecio a las ruinas creadas por la guerra. Belchite es fruto único del equilibrio entre ellas, y también de las políticas represivas ejercidas por la dictadura. Ello lo convierte en un catálogo extraordinario de los espacios soñados y realmente creados por el primer franquismo. Su estudio, por tanto, es de interés para conocer la naturaleza espacial de los proyectos del régimen.

\section{La reconstrucción de España y sus utopías: el nuevo espacio y las ruinas del antiguo}

La reconstrucción de España tras la guerra se movió entre el pragmatismo más prosaico y el idealismo propagandístico, este segundo el campo favorito de la retórica estatal. Pero, en este último ámbito, las propuestas y las pulsiones fluctuaban también entre dos polos, dos tipos de espacios ideales de tiempos opuestos: una utopía que se proyectaba en el futuro y otra que lo hacía en el pasado.

\section{La utopía proyectada en el futuro: el nuevo espacio de la nueva España}

Los teóricos falangistas, y más ampliamente quienes desde el régimen se dedicaron a adaptar a los nuevos tiempos planteamientos ya existentes, comenzaron a elaborar durante la guerra un plan general para una reordenación espacial, funcional y simbólica, de la patria. Uno de los campos más propicios a priori para plantear soluciones novedosas y de conjunto era el de aquellos lugares que por haber quedadodestruidos requerían su reconstrucción ${ }^{3}$.

1 Utilizo este adjetivo, que debe entenderse referido al partido único franquista creado en 1937, consciente de los problemas que su uso entraña.

2 La guerra había agravado los males endémicos de la vivienda rural y obrera.

3 Sobre la reconstrucción y Regiones Devastadas: Ureña 1979, Arquitectura en Regiones Devastadas 1987, López Gómez 1995, Almarcha 1997, Muñoz-Rojas 2011, Viejo-Rose 2011, Bitrián 2014. 
De las diversas medidas sobre proyectos de reparaciones anunciadas a finales de 1937 por el núcleo del bando sublevado, la más interesante para el objeto de este estudio es el plan para la reconstrucción de Guernica, que tras su elaboración por los Servicios Técnicos de la Falange fue presentado por Franco en una exposición inaugurada el 28 de diciembre en Burgos con el título "Reconstrucción nacional. Un ejemplo: Guernica". Para la prensa controlada por los rebeldes la Guernica reconstruida debía convertirse en "un modelo de lo que será la vida en la España de Franco" ${ }^{4}$. El programa de la exposición resaltaba al respecto:

Queremos que el hogar, célula permanente de la sociedad, sea amable: con aire y con sol: con lumbre y con pan: en las capitales y en los pueblos pequeños, hasta hoy abandonados, de nuestra Patria. El presente anteproyecto es un ejemplo de cómo será la vida en la España Imperial. (...) Pero la tarea que con santa ambición nos imponemos no se limitará a la reconstrucción de que lo el marxismo arrasó. Después de levantar sobre las ruinas las nuevas ciudades nacionalsindicalistas, llegaremos, con todo el ímpetu de nuestra "manera de ser", a cambiar radicalmente la estructura de la vida urbana y rural española5.

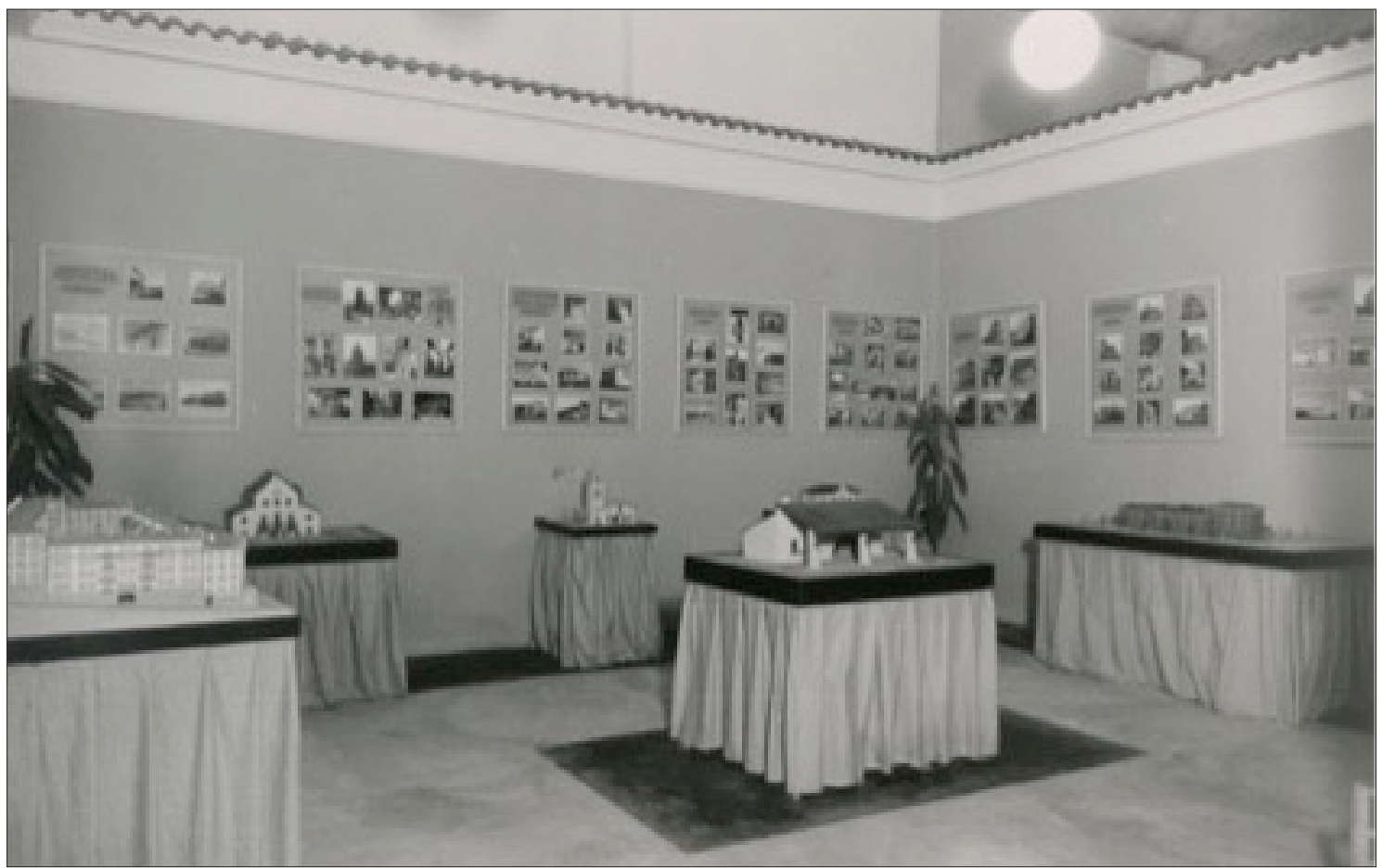

Figura 1. Exposición de proyectos de Regiones Devastadas en Valencia.

Fuente: AGA, RD, c. F4257.

El modelo de ciudad ejemplar planteado en este primer momento por el régimen puede ser trazado a partir de algunas formulaciones teóricas y determinados proyectos. El ideal era en cierta medida un híbrido entre la ciudad tradicional y la moderna. De la medieval tomaba su carácter limitado y orgánico, la legibilidad de la forma y el perfil, la organización en torno de la plaza mayor porticada como espacio político representativo, y la supremacía en los procesos de conformación urbana de lo institucional, lo religioso y lo corporativo por encima de lo económico y especulativo. De la ciudad industrial (y también de las aspiraciones del movimiento mo4 ABC (Sevilla), 29 de diciembre de 1937, p. 19.

5 Losada 1937, p. 11. 
derno en aquel momento en desarrollo) tomaba asimismo gran número de características: la seriación tipológica, el predominio de la nueva vialidad, la amplitud de los espacios, la incorporación de grandes zonas verdes, la importancia de las redes de suministros y servicios, el predominio de la salubridad y la higiene en la planificación urbana o un amplio despliegue del programa dotacional' .

Como sucedió con el intento paralelo de crear una arquitectura nacional, el de crear un tipo de ordenación urbana propio resultó en buena medida frustrado, y con el tiempo quedó desplazado por el modelo general de desarrollo capitalista. Pero en los inicios del franquismo, la de la nueva ciudad era una de las utopías más interesantes para los técnicos e ideólogos del régimen.

\section{La utopía proyectada en el pasado: el espacio de las ruinas gloriosas}

El proyecto para Guernica, que aquí nos interesa especialmente porque prefigura el de Belchite, no consistía únicamente en la creación de una nueva ciudad de espacios funcionales, pues también incluía la conservación de las ruinas causadas por unos bombardeos que el régimen pretendía hacer pasar por ataques republicanos7.

Es coherente con el ambiente del aparato nacionalista que su primer proyecto de reconstrucción urbana no hiciese desaparecer las ruinas causadas por la guerra. Desde que el ejército de la República redujera a escombros buena parte del alcázar de Toledo, las ruinas se habían erigido en el imaginario nacionalista en una de las principales manifestaciones de su sacrificio, así como de la vesania del enemigo ${ }^{8}$. Pronto se descubrió, además, que las ruinas narraban, que el relato se impregnaba perfectamente en los restos físicos y se diseminaba de manera muy efectiva a través de su imagen. Las palabras de Agustín de Foxá en Vértice son representativas del sentimiento generado:

Necesitamos ruinas recientes, cenizas nuevas, frescos despojos; eran precisos el ábside quebrado, el carbón en la viga y la vidriera rota para purificar todos los salmos.

Ambicionábamos ofrecer claustros y columnas truncados, yesos y molduras caídos. Y era que España dormitaba. (...)

Pero ya está Toledo derruído; es decir edificado.

España varonil, desvelada, inesperada, tiende sobre la mesa sus planos de ciudades en ruinas exalta la arquitectura heroica de sus fortalezas minadas. (...)

Benditas las ruinas porque en ellas están la fe y el odio y la pasión y el entusiasmo y la lucha y el alma de los hombres. (...)

Porque hemos conocido el dolor, sabemos ya de la hermosura de la ruina9.

A partir del mito creado en torno del Alcázar, las ruinas de la guerra pasaron a tener un destacado componente movilizador, moralizador y propagandístico. Allá donde fue posible aunar un relato heroico con una imagen de devastación causada por el ejército republicano, las ruinas se convirtieron en símbolos. El Alcázar de To-

6 D'Ors 1937, D’Ors 1938, Ideas generales... 1939, Texto de las sesiones... 1939.

7 Losada 1937, p. 11.

8 Muñoz-Rojas 2011, Viejo-Rose 2011, Bitrián 2014, Michonneau, 2014.

9 Foxá 1937. Parcialmente reproducido en: Mainer 1971, p. 43. Y más ampliamente en: Rodríguez 2008 , pp. 294 y 295. 
ledo, el santuario de Nuestra Señora de la Cabeza, el cuartel de Simancas en Gijón, el cerro de los Ángeles en Getafe, el Seminario de Teruel, el cuartel de la Montaña, la Ciudad Universitaria y, desde luego, Belchite, pasaron a ser los hitos principales de un paisaje que, por otra parte, se reproducía a escala local. Se trataba de una estrategia audaz: las ruinas, aquello que en mayor medida se genera en el espacio durante una guerra, se convertían así en recursos movilizadores, en dispositivos contenedores de relatos a difundir y ejemplos a seguir.

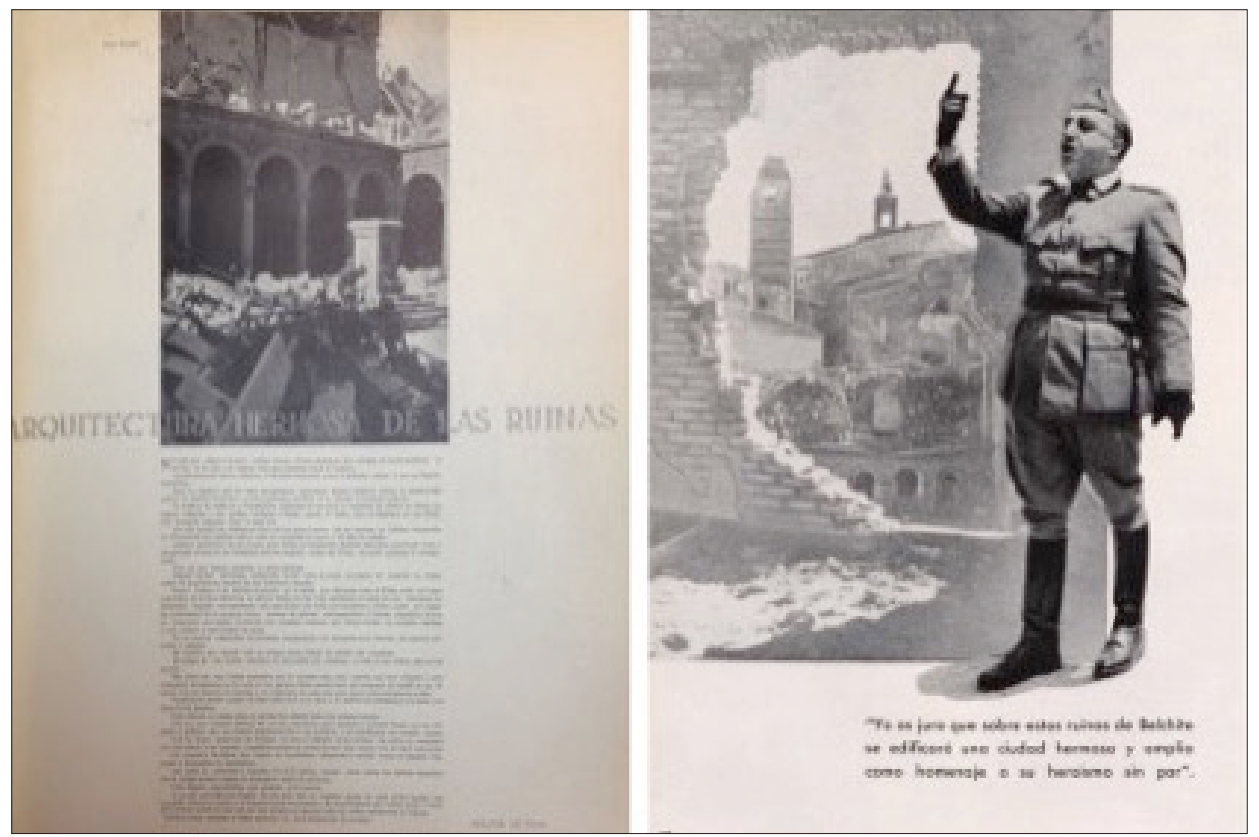

Figuras $2 a$ y 2 b. Páginas dedicadas a las ruinas en las revistas Vértice (izquierda) y Reconstrucción.

Fuentes: Vértice, abril de 1937, n. 1 (izquierda) y Reconstrucción, abril de 1940, n.1, p.10

Aunque se ha señalado la influencia del nazismo, y especialmente la del arquitecto y político Albert Speer ${ }^{10}$, creo que el interés no proviene de ahí ${ }^{11}$, sino más bien de la atención recibida por las ruinas recientes tras la Gran Guerra ${ }^{12} y$, sobre todo, en la fascinación de algunos movimientos de vanguardia por la modernidad y la destrucción de las estructuras establecidas ${ }^{13}$. A raíz de la primera Guerra Mundial las ruinas adquirieron cierto carácter de oportunidad ${ }^{14}$, en el marco de un urbanismo que, como muestran proyectos como el plan Voisin de Le Corbusier para el centro de París, sentía una pulsión por una renovación total de los tejidos urbanos.

La inestable violencia que caracteriza el culto a las ruinas surgido en el seno del falangismo solo se entiende, en mi opinión, en un marco de guerra, en el que el interés se proyecta sobre el puro presente, y no sobre el pasado lejano (como en el caso de las ruinas antiguas) o sobre el futuro (como en el caso de las ruinas que 10 Sambricio 1977, p. 23. La relación se sugiere también, aunque más matizadamente, en: Sambricio 2016, p. 246.

11 Debe tenerse presente sobre la cuestión: Mittig 1993, p. 21 y Holtorf, 2000-2008.

12 Blanco 1987, p. 20-21. Box 2008, p. 187.Y: Hernández 2007, p. 67.

13 Baste con leer el manifiesto futurista para constatar el carácter provocadoramente violento de algunas propuestas. Marinetti 1909.

14 Sobre la recepción de esta visión en España, véase, por ejemplo: Calvet 1916, p. 14. 
dan lugar a grandes renovaciones). Tal vez la resistencia a renunciar a la tradición que caracteriza según algunos autore ${ }^{15}$ la recepción en España del futurismo podría explicar el valor dado a la ruina como manifestación de ruptura, pero como una manifestación y ruptura memorables. En todo caso, el de las ruinas se convirtió en uno de los espacios utópicos en los tiempos de forja del nuevo régimen.

\section{Tensión entre las dos utopías: la reconstrucción y las ruinas}

Cuando el Estado comenzó a preparar la reconstrucción sistemática de lo dañado por la guerra, todavía durante la contienda, se planteó una cierta ambigüedad entre las propensiones a la reconstrucción y a la conservación de las ruinas, entre una pulsión técnica y otra estética, y ello en el marco de las tensiones entre los diversos sectores del régimen ${ }^{16}$. Mientras Regiones Devastadas se preparaba para la reconstrucción, ciertos ámbitos del falangismo ${ }^{17} \mathrm{y}$ del Gobierno, defendían, como el jefe del Servicio Nacional de Bellas Artes Eugeni d'Ors, que deberían evitarse, “en lo posible, las reedificaciones. Las ruinas venerables deberían ser adecentadas sí, pero que nadie borre en ellas los estigmas de su pasión"18.

Después de la guerra el régimen siguió explotando el valor de las ruinas ${ }^{19}$, pero más en su imagen que en su realidad espacial. La gobernabilidad pasaba por la normalización, y la normalización por el borrado de los daños ${ }^{20}$. En este contexto se explican los titubeos iniciales en relación con la reconstrucción de lugares como el Alcázar de Toledo o Guernica. Esta villa asumió en un inicio, como hemos visto, el papel de combinar en un discurso urbano la reconstrucción y las ruinas ${ }^{21}$. Pero el proyecto, comenzado probablemente antes de la batalla de Belchite, planteaba en ese lugar problemas propagandísticos insalvables. Una vez reconquistada, sobre la villa aragonesa (de relato mucho más favorable) recayó la responsabilidad de transmitir mediante la experiencia del espacio el mensaje maniqueo del régimen.

\section{La "operación Belchite"}

\section{La batalla y el mito de Belchite}

La denominada batalla de Belchite, episodio bélico al que quedó prácticamente reducida la ofensiva republicana sobre Zaragoza que en el verano de 1937 pretendía evitar la caída del frente del norte ${ }^{22}$, fue tratada por ambos bandos como un éxito respectivo. Belchite ya era antes de la batalla, por sus características y su situación

15 Lentzen 1989, pp. 311-312.

16 López Díaz 2003.

17 Orientación Española, 15 de mayo de 1938, n. 17. Recogido en: Llorente Hernández 1995, p. 216.

18 López Aranguren 1945, p. 268.

19 Llorente 1995, p. 217.

20 Bitrián 2014, p. 255-262

21 Las "rutas de guerra" (ABC (Sevilla), 8 de junio de 1938, p. 11), de las que Belchite sería nodo, fueron creadas en 1938 con parecida lógica a la que después dio lugar al "símbolo de los dos Belchites": a través de ellas debían poderse comparar los dos modelos nacionales en liza (Fernández 1938, p. 3. Y: Martín 1937, p. 7).

22 Teira 2008. 
en pleno frente de Aragón, una villa destacada para ambos ejércitos ${ }^{23}$. Pero no cabe duda que tras el verano de 1937 la población aumentó su importancia y se convirtió en el centro de otra lucha, en este caso propagandística.

Para la República, el nombre y el episodio de Belchite quedaron asociados, como dijo el diputado de Esquerra José Antonio Trabal, al "progreso ascensional de nuestra organización ofensiva"24. Al paraestado franquista, la resistencia de los ocupantes de la población le ofreció una oportunidad para reaccionar en el campo de la propaganda al éxito republicano en la denuncia del ataque a Guernica. Muy pronto se difundió en la España de Franco la historia de una pequeña y heroica población cercada, sin posibilidad de recibir ayuda exterior, que pese a los ataques sañudos de un ejército muy superior se había sacrificado numantinamente por la patria. Lo sucedido en Belchite permitía la construcción del mito bélico preferido del franquismo, aquel que podía presentar a la verdadera España como el núcleo que resiste a los ataques de las fuerzas que pretendían desintegrarla. De modo que, nada más acabada la batalla, la prensa nacionalista comparó la gesta con la del Alcázar ${ }^{25}$ y anunció la epifanía del nuevo mito ${ }^{26}$.

El propio Franco refrendó el papel de Belchite. El propagandista Víctor Ruiz Albéniz, publicó en octubre de 1937 unas palabras suyas mediante las que destacaba la "misión histórica" del pueblo:

Lo de Belchite fue algo glorioso. De pocos hechos puede estar España más orgullosa que de este. Yo no lo estoy de ninguno ${ }^{27}$.

Durante los meses siguientes a la batalla, Belchite fue el centro de visitas oficiales, rutas turísticas, celebraciones populares y todo tipo de actos y homenajes. A finales de 1938 "las ruinas gloriosas de Belchite" eran ya, para el diario ABC, un "centro de peregrinaciones espirituales"28.

\section{"El símbolo de los dos Belchites"}

Significativamente, el 13 de marzo de 1938, horas después de la caída del frente de Aragón, Franco se trasladó a Belchite para celebrar la victoria y pronunciar un discurso. Un fragmento del mismo fue más tarde considerado ejemplo paradigmático de las promesas reconstructoras del régimen:

23 En relación con la fascinación sobre el ejército republicano: Thomas, p. 784. En relación con el bando franquista, es muestra el expediente para la concesión de honores, de lo que ofrezco información en mi tesis doctoral. Véase también: ABC (Sevilla), 7 de septiembre de 1937, pp. 6 y 7. Y: ABC (Sevilla), 14 de octubre de 1937, p. 13.

24 Trabal 1937. Que Belchite fuera el nombre de uno de los vehículos que participó en la liberación de París es una muestra de la memoria del suceso entre los republicanos españoles.

25 Es un ejemplo el artículo titulado "Alcázar de Adobes": Aragonés 1937.

26 ABC (Sevilla), 7 de septiembre de 1937, pp. 6 y 7.

27 Publicado por "El Tebib Arrumi" en Heraldo de Aragón el 21 de octubre de 1937. De Frutos 1944, p. 21-22.

$28 A B C$ (Sevilla), 18 de octubre de 1938, p, 11. 
Yo os juro que acabada la guerra, (...) a estos campos sedientes llegará el agua que los fecunde para que no falte el pan en ningún hogar, y que sobre estas ruinas de Belchite se edificará una ciudad hermosa y amplia como homenaje a su heroísmo sin par $^{29}$.

Aunque en este momento Franco no anunció la conservación de Belchite como un conjunto en ruinas, el Gobierno lo hizo poco después. El 16 de abril el ministro del Interior Ramón Serrano Suñer anunció que "las ruinas de Belchite serán respetadas, pero junto a ellas se levantará una gran ciudad". Para ese momento la propaganda oficial tenía ya muy claro el objetivo de algo que después se llamó "el símbolo de los dos Belchites":

Cuando la guerra acabe, se impondrá en las escuelas nacionales una obligada excursión de los niños mayorcitos a Belchite y una conferencia de sus maestros sobre el simbolismo de tan santas y preciosas ruinas. ¿Qué enseñanza mejor? (...) El pensamiento, pues, del Caudillo es bien claro: levantar una nueva ciudad de Belchite. y no importa que no sea levantada sobre las mismas ruinas, pues éstas, debidamente cerradas con un muro circundante, serían siempre para la posteridad un monumento viviente de la raza, testimonio perenne del heroísmo de un pueblo que antes quiso sucumbir que claudicar ni rebelarse, por amor a la Patria y por obediencia al Caudillo ${ }^{30}$.

Días más tarde el recién creado Servicio de Regiones Devastadas explicó a la prensa la operación a realizar ${ }^{31}$ :

Estas ruinas quedarán como reliquias. Se señalarán las que fueron calles de San Ramón, del Salvador y de San Roque. La heroica vía que va desde la Plaza Nueva a la carretera de Cariñena (...).

Quedarán las ruinas de Belchite. (...) Quedarán todas estas ruinas como monumento nacional y relicario. Y junto a ellas, en un terreno firme y sano, se alzará un nuevo Belchite, según prometió el Generalísimo. (...)

Será la nueva ciudad alegre en su trazado, de puro estilo aragonés, valeroso y fuerte.

Nos entregaron unas ruinas. Ante ellas, la voluntad constructiva levantará una ciudad nue$\mathrm{va}^{32}$.

Belchite no fue el pueblo más dañado, ni mucho menos. La de crear un pueblo nuevo y asimismo unas ruinas de guerra fue una decisión política. Nada obstaba a la reconstrucción de las edificaciones y los tejidos dañados y, posiblemente, hubiera resultado más económico.

El proyecto de Belchite puede comprenderse únicamente si se consideran las especiales circunstancias que concurren en el caso. La primera de ellas es la existencia de esas dos utopías proyectadas hacia tiempos diversos. Y la segunda, que la decisión tomada se adoptó y se hizo pública a las pocas semanas de creado el Servicio Nacional de Regiones Devastadas. Es muy posible que, si se hubiera pospuesto toda decisión sobre la reconstrucción, como se hizo en el caso del Alcázar o de Guernica, Belchite hubiese sido reconstruido en la posguerra. Sin embargo, el régimen, que

29 Heraldo de Aragón, 15 de marzo de 1938, portada.

30 Orlando 1938. Citado en: Teira 2006, p. 44, y en: Teira 2008, p. 43.

31 Sánchez del Arco (1) 1938.

32 Sánchez del Arco (2) 1938, portada. Más tarde insistía en ello el jefe de Regiones Devastadas: ABC (Sevilla), 21 de mayo de 1938, p. 10. 
llevaba meses coqueteando con la posibilidad de consagrar un espacio al culto a las ruinas, necesitaba un símbolo hecho con ellas durante la guerra, y eligió Belchite de entre todas las posibilidades existentes. No es de extrañar que fuera Belchite el lugar escogido para equilibrar ambas tendencias a través de un símbolo: sus ruinas tenían un valor monumental y estético, podían ser fácilmente asociadas a un relato épico con las características de los preferidos por el franquismo (no como Guernica o Corbera de Ebro), se encontraba cerca de una gran ciudad pero no en el medio de una (como el Alcázar, el cuartel de Simancas o la ciudad Universitaria), y no era un santuario religioso cuya devoción exigiera su restauración (como Santa María de la Cabeza o el Cerro de los Ángeles).

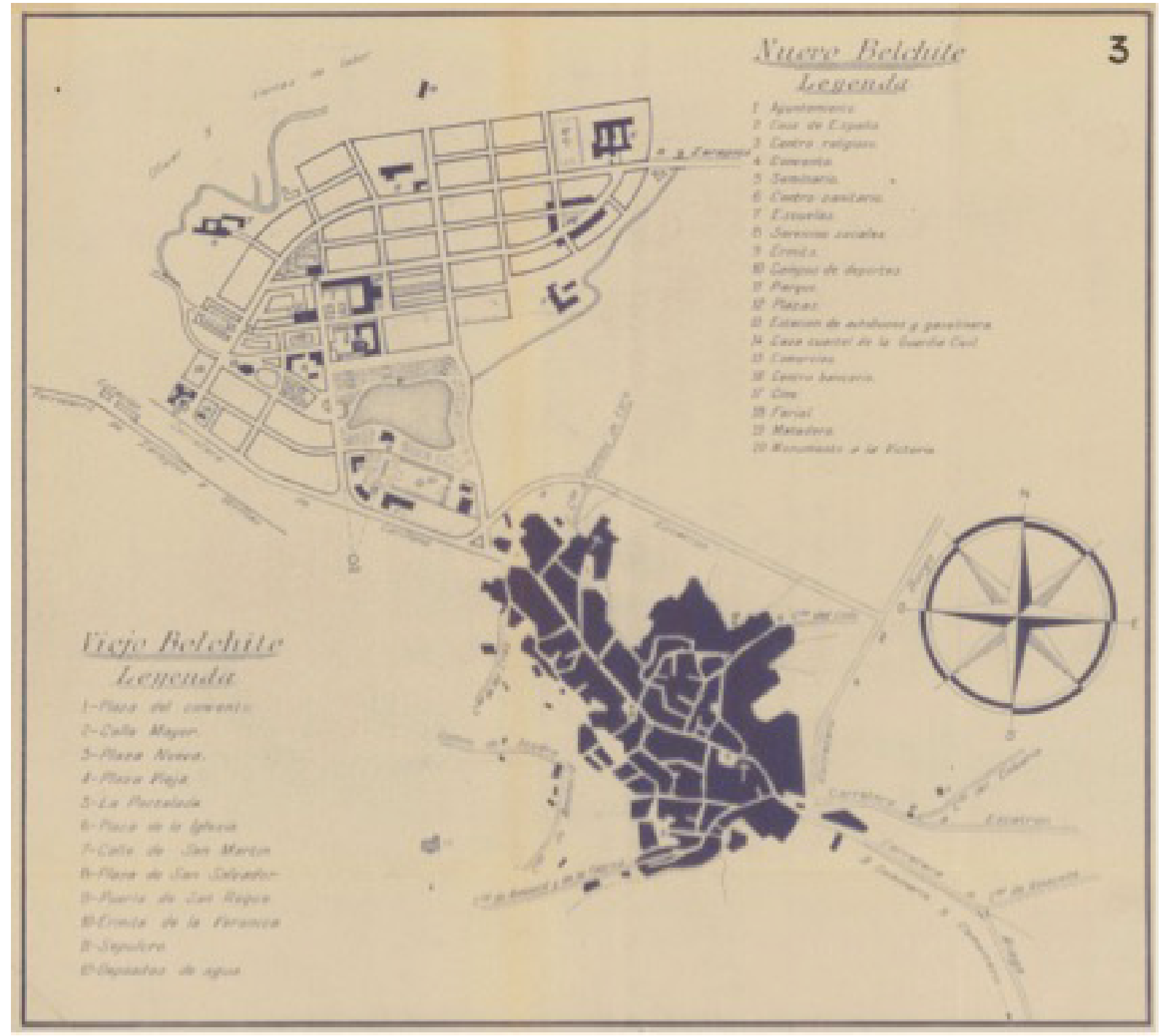

Figura 3. Plano de los "dos Belchites" realizado por Regiones Devastadas tras el fin de la guerra. Fuente: AGA, RD, c. 20702.

Así que a Belchite le cupo la responsabilidad de convertirse en depósito memorial no solo de un episodio heroico sino de la síntesis del discurso del régimen. Belchite debía mostrar la reconstrucción moral de España sobre las ruinas dejadas por la República y cristalizar la idea del contraste entre la capacidad creativa del ré- 
gimen y la maldad destructora republicana, y ello creando un santuario para el culto nacional a las ruinas. Todo ello se aprecia magníficamente en el artículo publicado en el primer número de la revista de Regiones Devastadas, titulado "El símbolo de los dos Belchites":

Junto a las piedras heroicas del viejo Belchite va a alzarse la traza cordial y acogedora del Belchite nuevo; junto a los escombros, la reconstrucción; junto al montón de ruinas que sembró el marxismo como huella inequívoca de su fugaz paso, el monumento alegre de la paz que la España de Franco edifica. Símbolos de dos épocas y de dos sistemas, los dos Belchites hablan, con el lenguaje mudo de los escombros y de sus blancas piedras, de barbarie y cultura, de miseria y de imperio, de materia y de espíritu, de la anti-España sojuzgada y de la España vencedora y eterna. (...) Porque es Belchite un símbolo, quiso el Caudillo conservarlo en el dolor de sus paredes calcinadas. (...) No puede haber más alto monumento a la memoria insigne de aquel puñado de héroes que el panorama torvo de las ruinas: con los boquetes que horadó la metralla, bien pronto taponados con carne palpitantes, aún más tenaz y firme que la piedra; con las desgarraduras de las casas, muñones aún en pie por patente milagro de la gloria; con las mellas profundas de los un tiempo airosos campanarios, en cuyo ápice roto se yergue todavía, aupada hacia las nubes y hacia la eternidad, la invencida promesa de una cruz. Relicario de mártires y de héroes de una mejor España, por decisión resuelta del Caudillo conservará Belchite el intacto prestigio del destrozo, un hito más en la larga cadena de epopeyas que jalonan por los campos de España la renovación de nuestra Historia que ha sido el Alzamiento Nacional ${ }^{33}$.

El símbolo de los dos Belchites suponía la traslación al espacio del mito que había dado lugar a la guerra civil, un mito que había llevado al extremo la idea de las dos Españas, tan enfáticamente defendida en la pastoral en la que el obispo de Salamanca, Enrique Pla y Deniel bendijo el golpe y la guerra en nombre de la Iglesia española. Esas dos ciudades de la pastoral, la del orden de los "Hijos de Dios" y la de la destrucción de los "Sin Dios" e "hijos de Caín"34 , esas dos Españas, podían dejar de ser ideas abstractas y convertirse en lugares experimentables. Así Belchite devino en símbolo. Pero para ello no solo el nuevo: todos los Belchites tuvieron que ser construidos.

\section{Espacios utópicos y heterotópicos en el primer franquismo: Los cinco Belchites}

\section{Las utopías de los dos Belchites}

El símbolo de los dos Belchites requería de dos espacios cercanos y radicalmente diferentes. Pueblos viejo y nuevo recibieron la misión de representar cada uno de ellos una de esas dos utopías del primer franquismo de las que hemos hablado.

\section{Belchite Viejo}

Belchite no presentaba ni un estado irreversible ni especiales dificultades para su reconstrucción ${ }^{35}$. La destrucción se concentraba en puntos estratégicos como las

33 Gómez Aparicio 1940.

34 Montero 1961, pp. 688-708.

35 Además del imprescindible libro con fotografías del archivo Allanegui (Allanegui, Archilla y Cinca 2008), deben considerarse las fotografías del Archivo General de la Administración (en adelante AGA) y las aéreas conservadas en el Archivo del Ejército del Aire en Villaviciosa de Odón. 
puertas de la ciudad o el entorno de la plaza Nueva. Pese a todo, las circunstancias ya vistas determinaron el tipo de intervención en la villa.

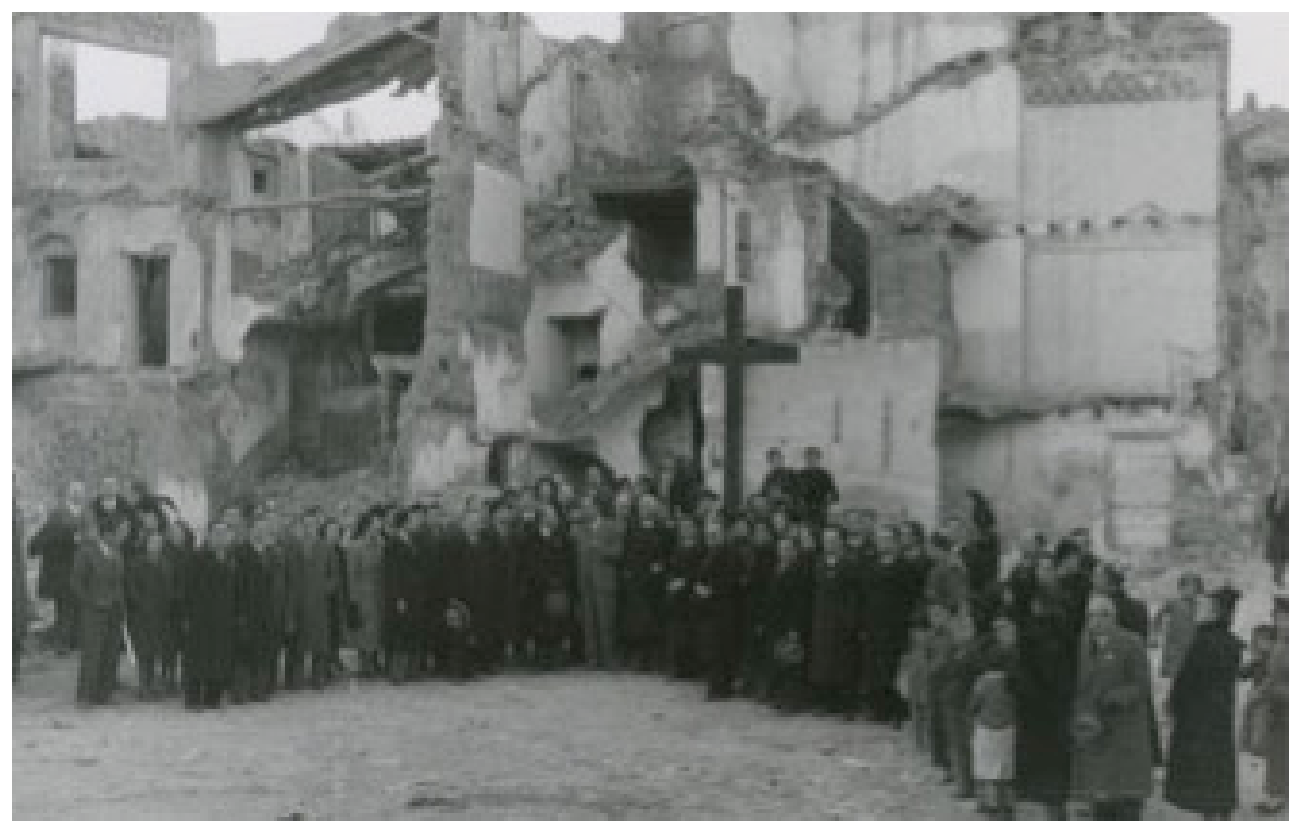

Figura 4. Acto de exaltación celebrado en una de las zonas más dañada del pueblo viejo de Belchite.

Fuente: AGA, RD, c. F4253.

El plan de reconstrucción de Belchite aprobado por Regiones Devastadas preveía medidas como la "consolidación" de las ruinas o la construcción de las "puertas de la ciudad" o de un gran "Monumento a la Victoria" ${ }^{36}$. Pero la posibilidad de una intervención integral en el pueblo viejo se enfrentaba a un obstáculo difícil de vencer: Belchite volvió pronto a ser un pueblo habitado. En diciembre de 1938 el viejo caserío ya albergaba a 1691 personas ${ }^{37}$ y en 1940, a $2680^{38}$, más del $75 \%$ de las 3542 personas empadronadas en $1925^{39}$. Poco a poco, y pese a las reticencias del Gobier$\mathrm{no}^{40}$, las actividades de autorreconstrucción se fueron imponiendo $\mathrm{o}^{41} \mathrm{y}$ las autoridades llevaron a cabo algunas medidas para dotar de equipamientos provisionales a la población. Al poco tiempo en Belchite se había regresado a una relativa normalidad.

36 Archivo Histórico Provincial de Zaragoza (en adelante AHPZ), Regiones Devastadas (en adelante RD), Caja (en adelante c.) A8232, Expediente (en adelante e.) Viejo Belchite, Informe referente a la situación actual de Belchite.

37 Archivo Municipal de Belchite (en adelante AMB), Padrón municipal de 1938.

38 AMB, Padrón municipal de 1940.

39 AMB, Padrón municipal de 1924.

40 Mediante el decreto fundacional de Regiones Devastadas, de marzo de 1938, el Estado había prohibido las reparaciones de daños causados por la guerra, con algunas excepciones. El Gobernador Civil se quejó al alcalde de que a pesar de las prohibiciones se estaban realizando obras y exigía la suspensión de los trabajos no autorizados. AMB, C. 23, Correspondencia 1939, Oficio de 16 de junio de 1939. Documento recogido, sin la referencia, en: Allanegui, Archilla y Cinca 2008, p. 14. Y: Vázquez 2010, p. 245.

41 El ayuntamiento vendió materiales a los vecinos "que han tenido necesidad de ello". AMB, Libro de actas (en adelante a.) 1937-1939, sesión (en adelante s.) de 8 de julio de 1939, folio (en adelante f.) 42. Y: AMB, a.1939-1941, s. de 30 de marzo de 1940, f. 12. AMB, a.1939-1941, s. de 30 de abril de 1940, f. 16. 
De modo que por el momento la única medida asequible era la de proceder a la superposición sobre los espacios de la vida cotidiana de un dispositivo de memorialización. Es lo que se hizo, lentamente, para adecuar el lugar a las visitas, ritos, celebraciones populares y peregrinaciones. Como los "via-crucis patrióticos" que hacían escolares $^{42} \mathrm{o}$ los actos del 6 de septiembre. Una de las ceremonias más impactantes debió de ser la recreación de la ruptura del cerco con el cadáver del comandante Santa Pau, que repitió el recorrido por la "vía heroica" camino de Zaragoza ${ }^{43}$.

Se actuó en la iglesia de San Agustín para habilitarla como parroquial ${ }^{44}$. En el lugar de la muerte de Santa Pau se alzó una cruz a modo de discreto monumento ${ }^{45}$. En la plaza se colocó una cruz en recuerdo de los caídos en el bando vencedor que en 1945 fue sustituida por otra de filigrana metálica ${ }^{46}$, la fosa común del Trujal fue adecentada y convertida, en los últimos años de vida del pueblo viejo, en el monumento a los Héroes ${ }^{47}$; se colocaron placas ${ }^{48} y$, pasado el tiempo, se desarrollaron proyectos para monumentalizar el Seminario ${ }^{49}$.

Solo cuando el pueblo fue vaciándose (el centro de gravedad se trasladó de las plazas centrales primero a la plaza de Goya durante los años $40^{50} \mathrm{y}$ a la plaza nueva a partir de 1954-1955) el Estado pudo y tuvo que plantear iniciativas de conjunto. El ministerio de la Vivienda propuso en 1960 que "el mismo Viejo Belchite" se convirtiese en el monumento a la Victoria previsto en el plan de reconstrucción. Se proponía "la creación sobre el Viejo Belchite, de una zona forestal en la que se repueblen las Manzanas en ruinas, surcadas por las calles del viejo Belchite, y presidido el conjunto por algunos monumentos conmemorativos y ruinas consolidadas que creen puntos de atracción". Además, el proyecto contemplaba la delimitación de la zona de actuación a través del Plan General de Ordenación Urbana (que se redactó en $\left.1964^{51}\right)$, la adquisición de suelos y edificios, la "preparación de ruinas para la repoblación" forestal y la "consolidación de las ruinas que interese conservar entre la

42 Heraldo de Aragón, 16 de mayo de 1939, p. 2.

43 Heraldo de Aragón, 7 de mayo de 1939, p. 5.

44 AGA, RD, c. 1784, e. 4.

45 Heraldo de Aragón, 2 de mayo de 1939, p. 5. AMB, a.1942-1944, s. de 30 de octubre de 1943, f. 70. AMB, A. 1944-1948, s. de 31 de julio de 1947, f. 68.

46 AGA, RD, C. 20741, E. 3, Cruz de los Caídos. AMB, a. 1944-1948, s. de 30 de junio de 1945, f. 18. AMB, a. 1948-1950, s. de 9 de junio de 1948, ff. 3-4. AMB, a. 1948-1950, s. de 30 de mayo de 1949, f. 57.

47 En 1946, por ejemplo, se hicieron obras de reparación en el trujal. AMB, a. 1944-1948, s. de 15 de noviembre de 1946, f. 51. AMB, a. 1948-1950, s. de 15 de octubre de 1949, f. 71. AMB, a. 1954-1956, s. de 28 de febrero de 1955, f. 24. AGA, Dirección General de Arquitectura (en adelante DGA), c. 76/00139, Monumento a los héroes. AMB, a. 1959-1961, s. de 30 de julio de 1961, f. 95. El monumento, diseñado por Manuel Martínez de Ubago, fue entregado al municipio. AMB, a. 19611964, s. de 30 de octubre de 1962, f. 40.

48 AMB, a. 1961-1964, s. de 30 de mayo de 1962, f. 25.

49 AHPZ, RD, c. A8232, Copia de instancia de 25 de noviembre de 1964. AHPZ, RD, c. A8232, Informe de 15 de diciembre de 1964.

50 Un hecho polémico e importante a este respecto fue el traslado del ayuntamiento desde su sede histórica al antiguo cuartel de la Guardia Civil. AMB, a. 1939-1941, s. de 30 de octubre de 1940, f. 40.

51 AHPZ, RD, c. A8232. 
vegetación; (algo como lo ya hecho con la Torre de la Iglesia Parroquial)". También contemplaba el "monumento a los héroes" en la fosa del Trujal, en aquel momento en tramitación, y el "establecimiento de un local para la exhibición de fotografías y gráficos retrospectivos" 52 .

El objetivo presente en este proyecto entronca con la idea original. Consiste en la creación de un parque memorial en el que la experiencia de la devastación se vería muy controlada por el poder. Primaría sobre todo una red de hitos dramáticamente presentados que serían los encargados de asociar la destrucción a los elementos heroicos del relato épico. En ese contexto, era necesario borrar los restos de la vida urbana posterior a la guerra civil, pues el mensaje debía remitirse a un determinado periodo de tiempo.

De modo que poco después comenzó a ejecutarse un proyecto que, sorprendentemente, ha pasado desapercibido, incluso en la memoria de los propios habitantes de Belchite ${ }^{53}$. El Estado llevó a cabo una operación de derribo sistemático de los edificios conservados ${ }^{54}$. A lo ya señalado por Cinca, Allanegui y Archilla sobre el papel del "abandono, expolio y olvido, con la ayuda de la lluvia y el viento" en el "trabajo destructivo y lento, pero ininterrumpido" 55 , debe añadirse, por tanto, la acción directa del Estado, que no ha sido considerada hasta ahora.

En $1963^{56}$ y $1969^{57}$ y en los años $70^{58}$, aunque sin mucho éxito, hubo nuevos intentos en la misma línea: la señalización de los hitos monumentales, la repoblación forestal, la conversión del recinto en un parque memorial y la adquisición de la propiedad.

\section{Belchite Nuevo}

Tras un prolijo estudio dirigido en 1938 por los arquitectos de Regiones Devastadas José María Ayxelá y Enrique Ledesma, con la colaboración de los arquitectos Ríos y Borobio, la prensa anunciaba ya a finales de ese año que "la nueva ciudad de Belchite", que tendría tres zonas (centro rector, núcleo agrícola y núcleo industrial) sería “además de centro turístico de la guerra en Aragón, un pueblo modelo, sin perder

52 AHPZ, RD, c. A8232, e. Viejo Belchite, Informe sobre Belchite.

53 Antes se habían planteado diversos derribos, pero más puntualmente. AGA, RD, c. 1785, e. 6. Existen otras copias. Y: AGA, RD, c. 20737, e. 4. AMB, a. 1951-1954, s. de 16 de diciembre de 1953, f. 73. AMB, a. 1951-1954, s. de 6 de febrero de 1954, f. 81.

54 AGA, DGA, c. 76/00133, Proyecto de demolición parcial del pueblo viejo de Belchite. AHPZ, c. A8238, Expediente de datos generales del proyecto de demolición parcial del pueblo viejo. El hecho de que entonces algunas zonas continuasen habitadas hizo que quedaran en pie construcciones que, muy deterioradas, han sobrevivido hasta hoy, cada vez más menguadas.

55 Allanegui, Archilla y Cinca 2008, p. 15.

56 AHPZ, RD, c. A8235, Informe sobre la situación y el futuro de las ruinas del pueblo viejo de Belchite.

57 AHPZ, RD, c. A8232, e. Viejo Belchite, Informe de noviembre de 1969. AHPZ, RD, c. A8232, e. Viejo Belchite, Informe de enero de 1970.

58 AHPZ, RD, c. A8232, e. Viejo Belchite, Carta de 11 de noviembre de 1970. AHPZ, RD, c. A8232, e. Viejo Belchite, Informe de 17 de mayo de 1972. AHPZ, RD, c. A8232, e. Viejo Belchite, Nota informativa de 26 de abril de 1973. AHPZ, Fondo de la Delegación del Gobierno en Aragón, c. A8873, e. 2, Nota de 2 de abril de 1973. 
por ello el estilo tradicional de la arquitectura aragonesa" ${ }^{\prime 29}$. Para el momento de terminar la guerra ya existía un anteproyecto de la nueva ciudad, del que no se conoce mucho todavía, pero que es sensiblemente diferente al definitivamente ejecutado.
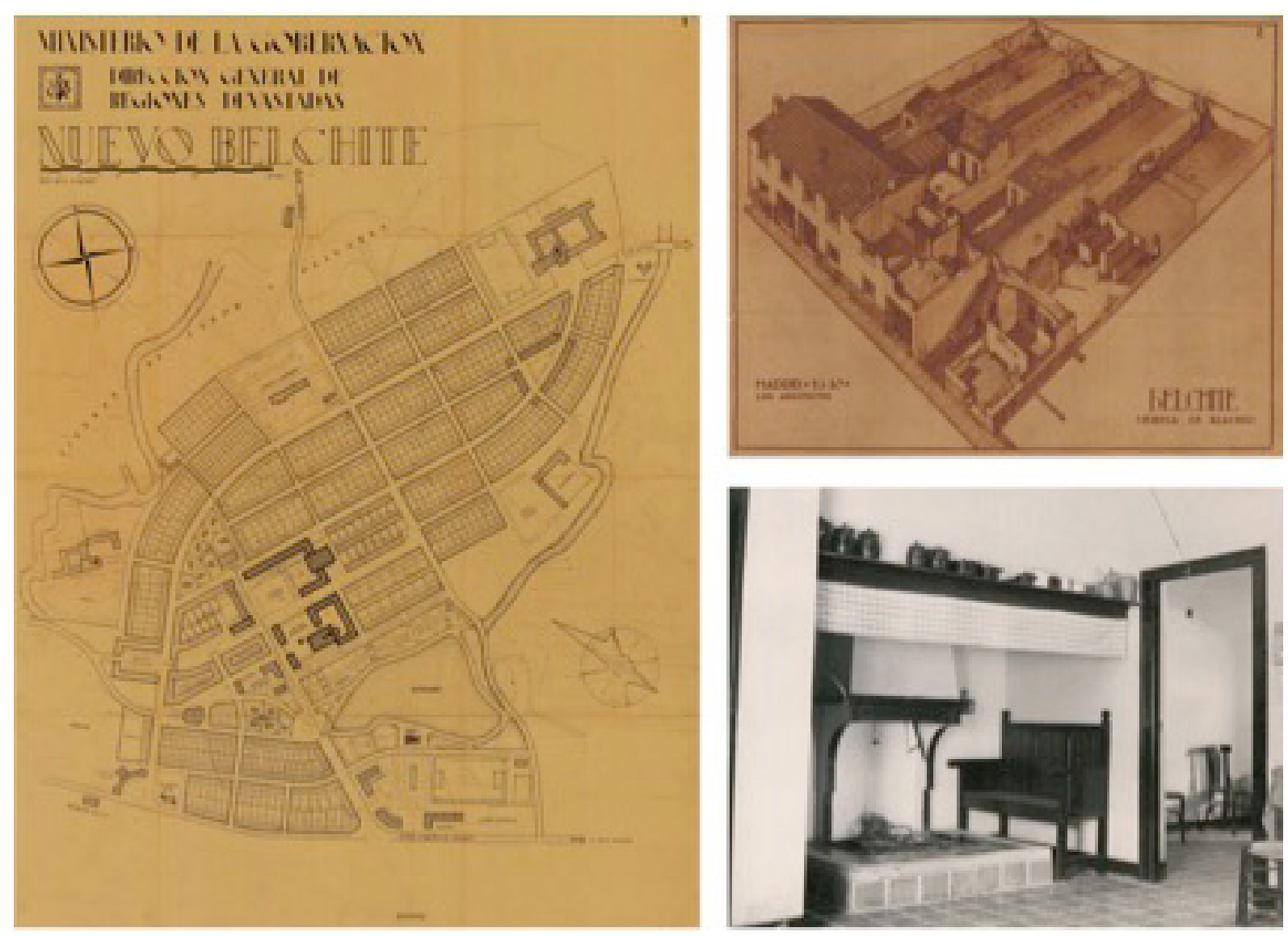

Figuras $5 a, 5 b$ y $5 c$. Belchite nuevo. Proyecto general (izquierda) y de viviendas (superior derecha) de 1940 y fotografía de un hogar (inferior derecha).

Fuentes: AGA, RD, c. 20702; AGA, RD, c. 20702 (izquierda y superior derecha) y AGA, RD, c. F4252.

En febrero de 1939 ya habían comenzado las obras ${ }^{60}$, aunque es de suponer que se trataría de trabajos preliminares, y en mayo ya se estaban construyendo las edificaciones auxiliares ${ }^{61}$. Poco después de la "adopción por el Jefe del Estado" de Belchite (que fue el primer pueblo "adoptado") en octubre de 193962, se aprobó el plan de adopción ${ }^{63}$. El proyecto definitivo (aunque posteriormente sufriría modificaciones menores) fue dado a conocer en abril de $1940^{64}$. La nueva población se concibió con una forma claramente definida y cerrada, almendrada gracias a las líneas curvas 59 Heraldo de Aragón, 23 de diciembre de 1938, portada. Y: ABC (Sevilla), 28 de diciembre de 1938, p. 20.

60 El avisador numantino, 25 de febrero de 1939, p. 4. Y: Labor, 27 de febrero de 1939, p. 3.

61 El Diario Palentino, 16 de mayo de 1939, p. 3.

62 Boletín Oficial del Estado (en adelante BOE), número 295, 22 de octubre de 1939, p. 5914.

63 AMB, a. 1939-1941, s. de 24 de febrero de 1940, f. 7.

64 La autoría del proyecto se ha atribuido a Francisco Echenique y Alfonso Fungairiño (López Gómez 1995, p. 338). Creemos que se trata de un proyecto con un grado importante de colaboración, aunque todavía faltan aspectos por aclarar. Por diferentes hechos cabe contemplar la posibilidad de la participación de Ledesma, Ayxelá, Echenique, Fungairiño, Cámara y, tal vez, Ríos, Borobio y Beltrán. 
que recogen la malla ortogonal que le sirve de base. Uno de los aspectos más interesantes del proyecto para el nuevo Belchite es su calculada ambigüedad respecto del grado de relación con las ruinas. El trazado está pensado para que pueda funcionar tanto autónomamente como de manera coordinada con el pueblo viejo, lo que permitía una fácil transición en el periodo de cohabitación y dejaba abiertas todas las decisiones futuras, como la de ensalzar las ruinas o la de olvidarlas. Las obras de las viviendas y los edificios oficiales comenzaron en $1940^{65}$ y las primeras casas se entregaron a finales del año siguiente ${ }^{66}$. Los trabajos, que transcurrieron a un ritmo lento que se fue acelerando a mediados de siglo por las diversas críticas y presiones, incluyeron numerosas modificaciones menores, entre las que nos interesa destacar, para subrayar el carácter modelo del pueblo nuevo, la inclusión a modo de cuña de una granja-escuela de la Sección Femenina. El equipamiento debía ser un centro irradiador de las nuevas doctrinas y costumbres para el mundo rural. En 1954 Franco inauguró la primera fase del pueblo nuevo y diez años más tarde fue entregada la segunda. A la muerte del dictador todavía había manzanas sin edificar.

Puede suponerse el impacto en la vida municipal de la fuerte presencia del Estado. En 1958 el ministro de la Vivienda declaró en Belchite la mayoría de edad de la villa y deseó que recobrase su independencia ${ }^{67}$.

\section{Heterotopías del primer franquismo: Los cinco Belchites}

Foucault creó el concepto de heterotopía para designar lugares reales, "localizables", creados como "espacios otros", extraídos del espacio "normal", o "natural", al que de alguna manera sirven. Lo utilizaremos aquí para designar los espacios de carácter disciplinario y subsidiario respecto de una suerte de espacio general, lo que Foucault denomina "heterotopías de desviación", es decir, "aquellas en las que se ubican los individuos cuyo comportamiento está desviado con respecto a la media o a la norma exigida"68.

En el momento en el que el régimen proclamaba su utopía espacial dual a través del "símbolo de los dos Belchites", en la población había, además del pueblo viejo y el nuevo en construcción, tres núcleos habitados más, tres heterotopías caracterizadas por la represión.

\section{Campo de concentración nacional}

Casi desde los inicios de la guerra civil el bando nacionalista creó un sistema concentracionario para los presos políticos que en la posguerra era ya amplio y desarrollado ${ }^{6}$. Según la Inspección de Campos, los que estaban bajo su control albergaban en febrero de 1939 a 237.103 presos $^{70}$.

65 Sin haber realizado las expropiaciones, en cuya financiación participó el ayuntamiento de Zaragoza. AHPZ, RD, c. A8220, Expropiaciones de Belchite.

66 Ese tan solemne día, el 12 de diciembre, el alcalde pidió que la nueva población se llamase "Belchite de Franco". AMB, a. 1939-1941, s. de 20 de diciembre de 1941, ff. 97-98.

67 AMB, a. 1956-1958, s. de 3 de Mayo de 1958, f. 65.

68 Foucault 1984.

69 Rodrigo 2008.

70 González 2011, p. 1028. 
La institucionalización del trabajo forzado fue acompañada de una elaboración retórica que tuvo como piezas centrales la proclamación del trabajo como "derecho" del preso ${ }^{71}$ y el concepto de "redención de las penas por el trabajo"72. Al Patronato Central se encargó "la ingente labor de arrancar de los presos y de sus familias el veneno de las ideas de odio y antipatria, sustituyéndolas por la de amor mutuo y solidaridad estrecha entre españoles" ${ }^{\prime \prime 3}$.

El trazado comprende una serie de recorridos y relaciones que a través de ejes visuales y diferentes hitos conectan ambos pueblos. Pero a la vez establece suficientes filtros (el parque de la Estanca es un ejemplo) como para mantener la independencia. Todo ello explica el desplazamiento geográfico del centro de la población, donde se concentra la zona de mayor carácter urbano. Los equipamientos se reparten alrededor de la periferia, y el tejido residencial destaca por una sutil zonificación en función de la clase social de los habitantes. El conjunto constituye un híbrido ntre un urbanismo de raíz funcionalista y una apariencia de guiños populares en la edificación residencial y de rasgos regionalistas en la pública ${ }^{74}$.

Los objetivos generales del sistema de explotación de los represaliados políticos eran el castigo, el aminoramiento del gasto de manutención, el aprovechamiento de la fuerza de trabajo y la reeducación de los presos para su inserción en el marco ideológico del régimen. Pero, en el campo de la reconstrucción, el sistema tenía también como objetivo el de señalar y visibilizar la responsabilidad sobre los daños habidos. Los conceptos de redención y reconstrucción quedaron hermanados en una determinada y peculiar concepción de la justicia. El director general de Prisiones lo sintetizó al afirmar en la inauguración de los Talleres Penitenciaros de Alcalá de Henares que eran "aquellos que habían destrozado España [los llamados] a reconstruirla"75.

Unos meses más tarde de que en noviembre de 1938 se dictaran normas para el uso de los prisioneros políticos en las obras de Regiones Devastadas ${ }^{76}$, el jefe del Servicio anunció la creación de un "Campo de Concentración" en Belchite para los presos que habrían de reconstruir la población ${ }^{77}$. Tras algunas gestiones relacionadas con los barracones ${ }^{78}$ y la escolta ${ }^{79}$, en abril ya había prisioneros en Belchite.

71 BOE, l de junio de 1937, n. 224, pp. 1698-1699.

72 Cuervo 1940, p. 28. Sobre Pérez del Pulgar: Núñez 1999, Núñez 2002, Gómez Bravo 2007, Gómez Bravo 2011, p. 827. Se trató de vincular el sistema con la "tradición imperial" española. BOE, 2 de mayo de 1939, n. 122, p. 2383.

73 BOE, 11 de octubre de 1938, n. 103, pp. 1742-1744, p. 1742.

74 Se trata de una obra colectiva cuya autoría es de Regiones Devastadas. En las edificaciones intervinieron, al menos, los siguientes arquitectos: Fungariño, Echenique, Chóliz, Martínez de Ubago, Lanaja y Pérez Páramo. También proyectaron Adrada (que dirigió las obras), Yarza, Garrido Serrano, Lagunas, De la Figuera, Boyer, Jalón y Allanegui.

75 Gómez Bravo 2011, p. 831. Cuervo 1940, p. 28.

76 Citado en: Gutiérrez 2004, p. 54.

77 AGA, RD, Cuartel General del Generalísimo (en adelante CGG), c. 26/17390. Oficio de 6 de febrero de 1939 del Jefe del SNRD.

78 AGA, RD, CGG, c. 26/17390. Oficio de 14 de febrero de 1939 del Jefe del SNRD.

79 AGA, RD, CGG, c. 26/17390. Oficio de 26 de marzo de 1939 del general Jefe de Estado Mayor. Y: El Diario Palentino, 16 de mayo de 1939, p. 3. 
El campo fue proyectado por el ingeniero Roque Adrada para “alojar 1.600 trabajadores", además de la escolta ${ }^{80}$. El recinto cercado estaba situado estratégicamente, junto a los terrenos del pueblo nuevo y cerca del viejo, de la estación de ferrocarril y del área de talleres. Los pabellones de planta única del campo se distribuían en torno de un patio central. 3 pabellones grandes y 10 más pequeños servían de dormitorios, y algunos otros tenían usos diversos, como cocina, comedor, escuela o enfermería. El patio estaba presidido por una capilla exenta y desalineada, dotada de un gran escudo de la España franquista sobre el arco de entrada con la leyenda "Por el Imperio hacia Dios", de una cruz de homenaje a los Caídos y de una gran bandera de España.

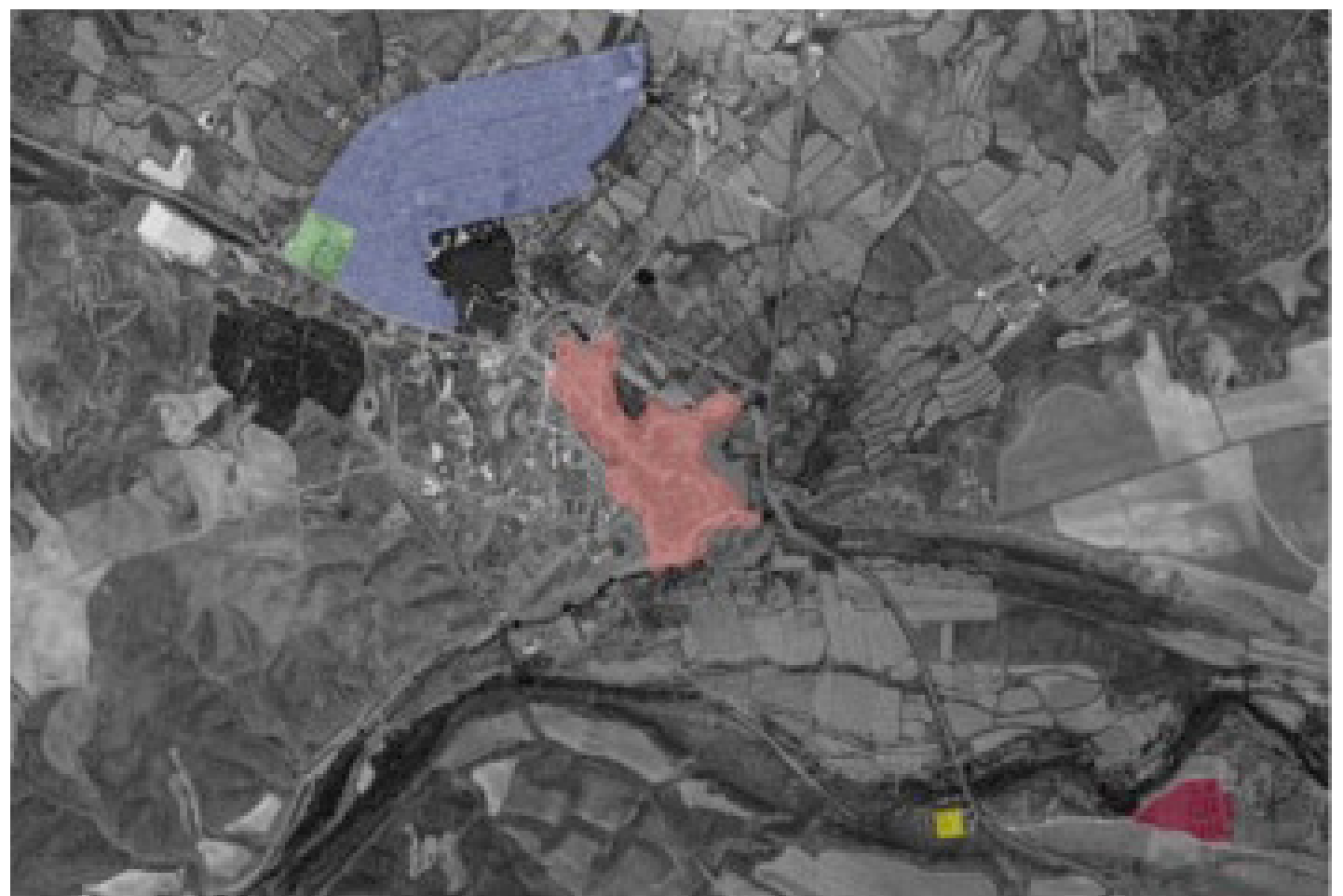

Figura 6. Los "cinco Belchites". En rojo, el pueblo viejo; en azul, el pueblo nuevo; en verde, el campo de concentración nacional; en amarillo, el campo de concentración internacional; y en magenta, Rusia.

Fuente: Elaboración propia a partir de fotografía tomada de http://idearagon.aragon.es.

Durante la primera mitad de la década de los años 40 el campo de concentración era el segundo núcleo más poblado de Belchite, tras el pueblo viejo. En 1940 había recluidos en el campo 1054 presos $^{81}$, más de un quinto del total de personas que entonces vivían en el municipio. Además, 113 militares residían en los pabellones de escolta. Dos años después habitaban el campo 1340 personas ${ }^{82}$.

Los 1.054 presos políticos registrados en 1940 tenían edades que iban desde los 19 a los 60 años, con una media de edad cercana a los 36. Salvo un preso, todos sabían leer y escribir, por lo que la tasa de alfabetización era muy superior a la de los

80 Al menos fue Roque Adrada quien firmó el proyecto oficial. AGA, RD, c. 20754, e. 4.

81 AMB, Padrón municipal de 1940.

82 AHPZ, Prisión Provincial (en adelante PP), Destacamento penal de Belchite (en adelante DPB), correspondencia, c. 5723/1, Copia del telegrama de 5 de febrero de 1942. 

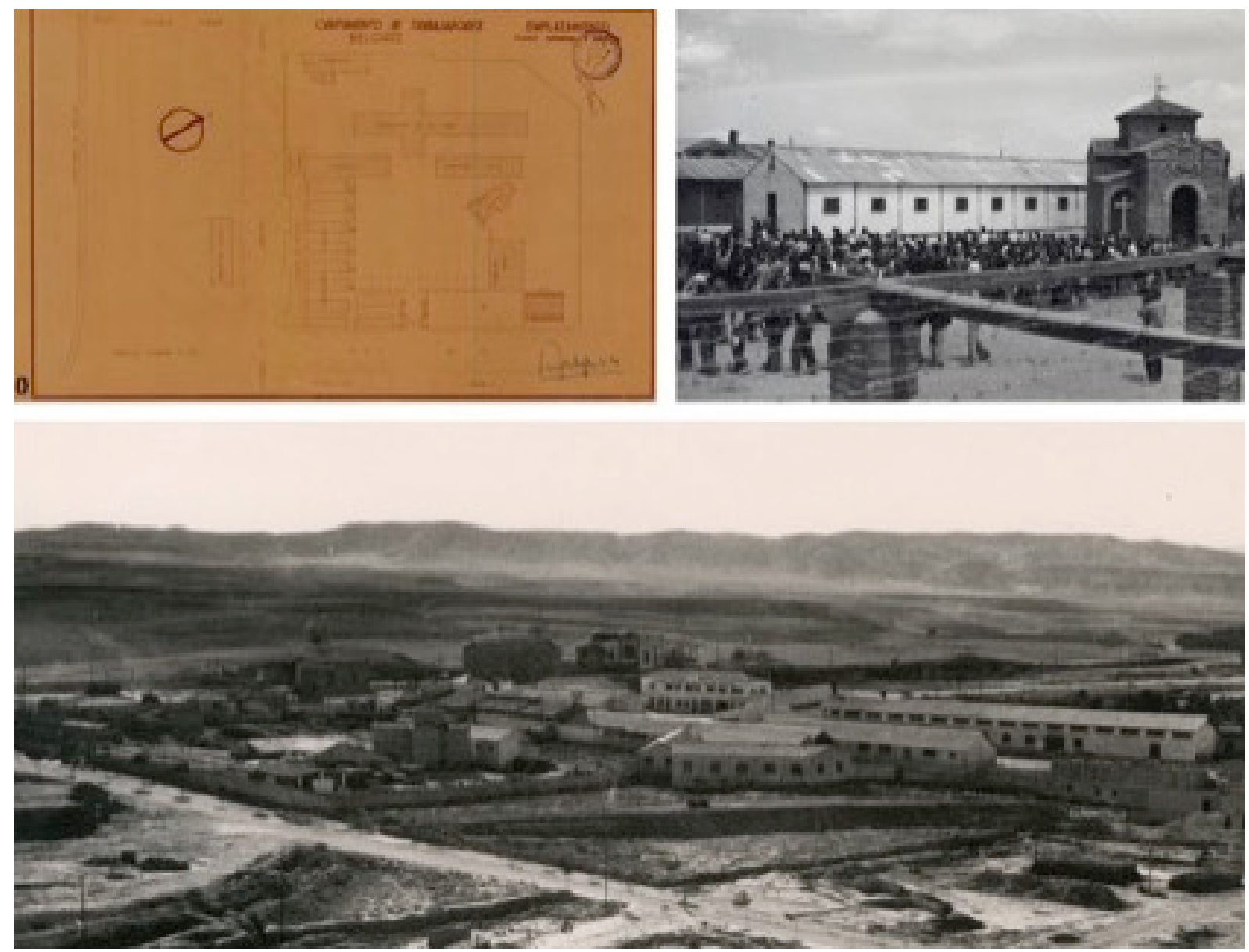

Figuras 7a, 7b y 7c. Campo de concentración nacional de Belchite. Planta (superior izquierda), imagen de una concentración en el patio central (superior derecha) y vista del conjunto (inferior). Fuentes: AGA, RD, c. 20754 (superior izquierda) y AGA, RD, c. F4250 (superior derecha e inferior).

naturales de Belchite. Dos tercios estaban casados, cerca del 30\% solteros y el resto viudos. Su origen era muy diverso. Aunque estaban representadas 42 de las 50 provincias españolas, Cataluña $(32,92 \%)$ y Aragón $(28,65)$ sumaban más del 50\% de la población total. También era muy variado el abanico profesional, pues había cerca de 80 oficios representados, que pueden agruparse en tres grupos, el de los trabajadores de la construcción no especializados (albañil, peón...), el de los trabajadores especializados (carpinteros, pintores, canteros y herreros principalmente) y el de los trabajadores del campo. Había también médicos, un sacristán, chóferes, cocineros... Los obreros especializados representaban aproximadamente el 70\% de la población reclusa, lo que muestra un importante proceso de selección de los prisioneros en Regiones Devastadas ${ }^{83}$. En todo el tiempo en que estuvo en activo, por el campo de Belchite pasarían alrededor de 5000 personas ${ }^{84}$.

El campo era el centro de una red de destacamentos penales mucho más pequeños para la reconstrucción de pueblos como Quinto de Ebro, La Puebla de Albortón

83 Cuando no ofrecían el rendimiento esperado, los presos eran devueltos a las prisiones. AHPZ, PP, DPB, correspondencia, c. 5723/1, Oficio de 3 de noviembre de 1941.

84 AHPZ, PP, DPB, c. 5640, 2. Libro índice de registro de entrada y salida de penados del campo de Belchite. 
o Rodén ${ }^{85}$. A partir de 1940 el Estado, que apenas podía sostener una población reclusa tan importante, comenzó una política de liberación provisional que se alargó durante toda la década. Así, algunos presos fueron sometidos a un régimen de libertad condicional que, en ocasiones, incluía el destierro de sus poblaciones de origen. Por ello no era infrecuente que se quedasen en Belchite. El indulto general concedido en octubre de 1945 hizo que la redención de la pena conseguida por el trabajo no tuviera efecto en la gran mayoría de los $\operatorname{casos}^{86}$.

El contacto de los vecinos con los presos era escaso, entre otras cosas porque los primeros necesitaban un salvoconducto para cruzar el espacio en el que podían trabajar los segundos. El ayuntamiento no puso, en general, las cosas fáciles a las familias, y más bien procuró que abandonaran la población ${ }^{87}$.

A finales de 1965 se ordenó el derribo de lo que quedaba del campo, pues en el terreno se pretendía construir un Silo del Servicio Nacional del Trigo. Aunque el municipio trató de conservar la capilla, el Estado no accedió a ello ${ }^{88}$, lo que es interesante, pues muestra la voluntad de deshacerse de un rastro de memoria que no resultaba conveniente cuando se acababan de celebrar los "XXV Años de Paz". Aunque el campo desapareció, todavía se conservan, olvidadas, algunas construcciones de los talleres anexos.

\section{Campo de concentración internacional}

Otra heterotopía belchitana es fruto de otro tipo de explotación de mano de obra reclusa, la que estaba camuflada en el seno del ejército y correspondía a personas ni penadas ni juzgadas ${ }^{89}$.

Tras la reconquista de Belchite se creó un Batallón de Trabajadores extranjeros, el número 27, en el que fueron ingresados los prisioneros hechos en las filas de las brigadas internacionales. El batallón fue enviado al campo de concentración de San Pedro de Cardeña, en Burgos, y se convirtió en el batallón disciplinario de trabajadores $n^{0} 75$. Comenzadas ya las obras de Belchite, en noviembre de 1939, fue ordenado "con la máxima urgencia" el traslado de los 459 prisioneros extranjeros del campo castellano $^{90}$. Javier Rodrigo ha señalado que los 300 prisioneros provenientes de Miranda de Ebro se unieron a los procedentes de San Pedro de Cardeña "en la actual zona del pueblo conocida popularmente como "Rusia»"91. Aunque no puede descartarse el uso inicial de otros espacios, los presos internacionales fueron instalados en el complejo del antiguo Seminario de Belchite ${ }^{92}$.

85 AHPZ, PP, DPB, correspondencia, c. 5723/1. Oficio de 5 de marzo de 1943.

86 Rodrigo 2008, p. 251.

87 AMB, a. 1942-1944, s. de 30 de diciembre de 1942, f. 39. AMB, a. 1944-1948, s. de 13 de enero de 1946, f. 33. AMB, a. 1944-1948, s. de 17 de febrero de 1946, f. 35.

88 AMB, a. 1964-1966, s. de 30 de septiembre de 1965, f. 74.

89 Beaumont y Mendiola 2006. Y: González 2011.

90 Rodrigo 2008, p. 253.

91 Rodrigo 2008. p. 255.

92 Así lo atestigua la memoria colectiva y algunos hechos, como la presencia en el padrón de un prisionero norteamericano del batallón 75 (Pallarés, Espinosa de los Monteros 2005, p. 175) o las declaraciones en 1941 de un evadido. España Popular, 3 de febrero de 1941, p. 6. 


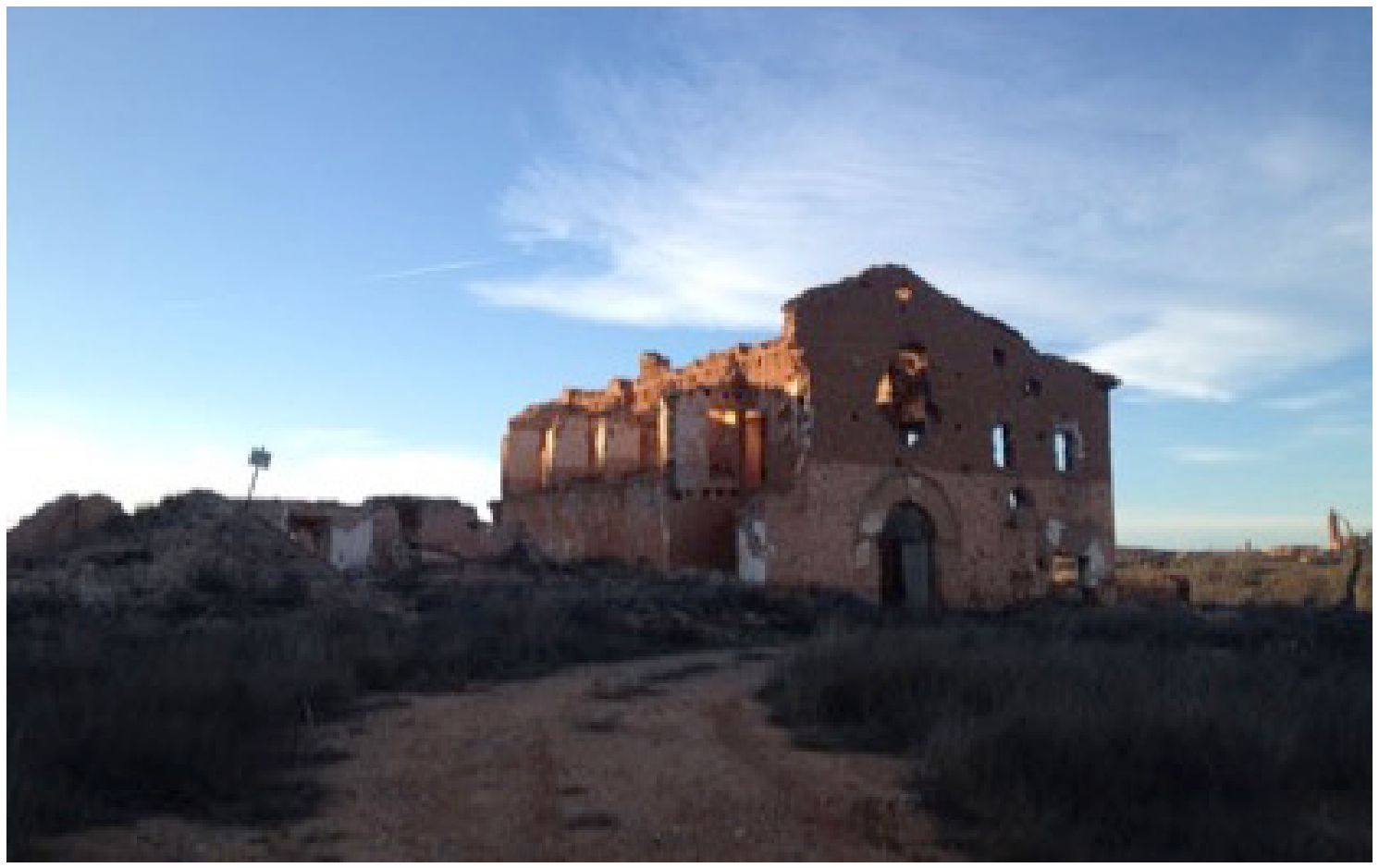

Figura 8. Ruinas de la iglesia del Seminario de Belchite en la actualidad. Fuente: Fotografía del autor.

En 1940 había 834 personas, de las que 360 eran militares y 474 eran presos que aparecen en el padrón como "trabajadores"93. 150 de ellos eran de nacionalidad española y 324 tenían otras nacionalidades. La tasa de alfabetización total era del 100\%. Los presos españoles tenían edades comprendidas entre los 18 y los 56 años y una edad media de casi 27 . El 76\% eran solteros, había un viudo y el resto eran casados. Provenían de 39 provincias diferentes y de Melilla, pero casi la mitad eran andaluces y valencianos. Sumaban entre ellos una cuarentena de oficios, aunque el más común era el de trabajador del campo, que ocupaba al 27,1 de la población. Había también un porcentaje alto de marineros (12\%) y de comerciantes $(6,9)$, y menor representación de albañiles, carpinteros, electricistas, mineros, barberos, cocineros, chóferes, confiteros, estudiantes, impresores, industriales, panaderos, pintores, sastres... Solo un 13,89\% tenía oficios directamente relacionados con la construcción, lo que denota un grado mucho menor de especialización que entre los "penados".

Los prisioneros internacionales tenían edades de 19 a 65 años, con una edad media de 29 años y medio. Los solteros eran también mayoría (75,93\%). No conocemos sus profesiones, pero sí sus nacionalidades. Había 31 diferentes. El grupo nacional más numeroso era el de argentinos, con el 19,14\%. Le seguían franceses (13,58\%), alemanes y polacos (9,87\%). Había al menos un ciudadano de los siguientes países: Holanda, Austria, Marruecos, Italia, Checoslovaquia, Ucrania, Yugoslavia, Hungría, Portugal, Grecia, Bulgaria, Estonia, Reino Unido, Rumanía, Uruguay, Chile, Cuba, Estados Unidos, Lituania, Albania, Andorra, Bélgica, Brasil, China, Filipinas, Méjico y

93 Esto es significativo porque en el caso de los prisioneros políticos nacionales aparecen como "penados". 
Suiza. La composición del campo puede relacionarse, aunque no es la misma, con la del batallón 75 trasladado a Belchite en noviembre de $1939^{94}$.

Los prisioneros del campo internacional fueron dedicados a tareas muy duras, como la extracción de piedra95 0 , según la memoria popular, la canalización de agua de boca de Almonacid de la Cuba a Belchite. Debido a las implicaciones diplomáticas de la reclusión de prisioneros internacionales forzados al trabajo ${ }^{96}$, el campo internacional de Belchite duró poco, y ya no estaba activo a finales de $1941^{97}$. El batallón pasó a Palencia y de allí al campo de Miranda ${ }^{98}$. Aunque muchos prisioneros fueron liberados, el batallón 75 fue uno de los que más tardó en ser disuelto ${ }^{9}$.

\section{Rusia}

A la vista de la importancia que la población había adquirido para el franquismo tras la reconquista, diversas organizaciones formadas al calor del nuevo régimen fijaron su atención en ella. Es el caso de Auxilio Social, fundado por Mercedes Sanz como Auxilio de Invierno en 1936 a imitación de la campaña nazi Winterhilfe ${ }^{100}$.
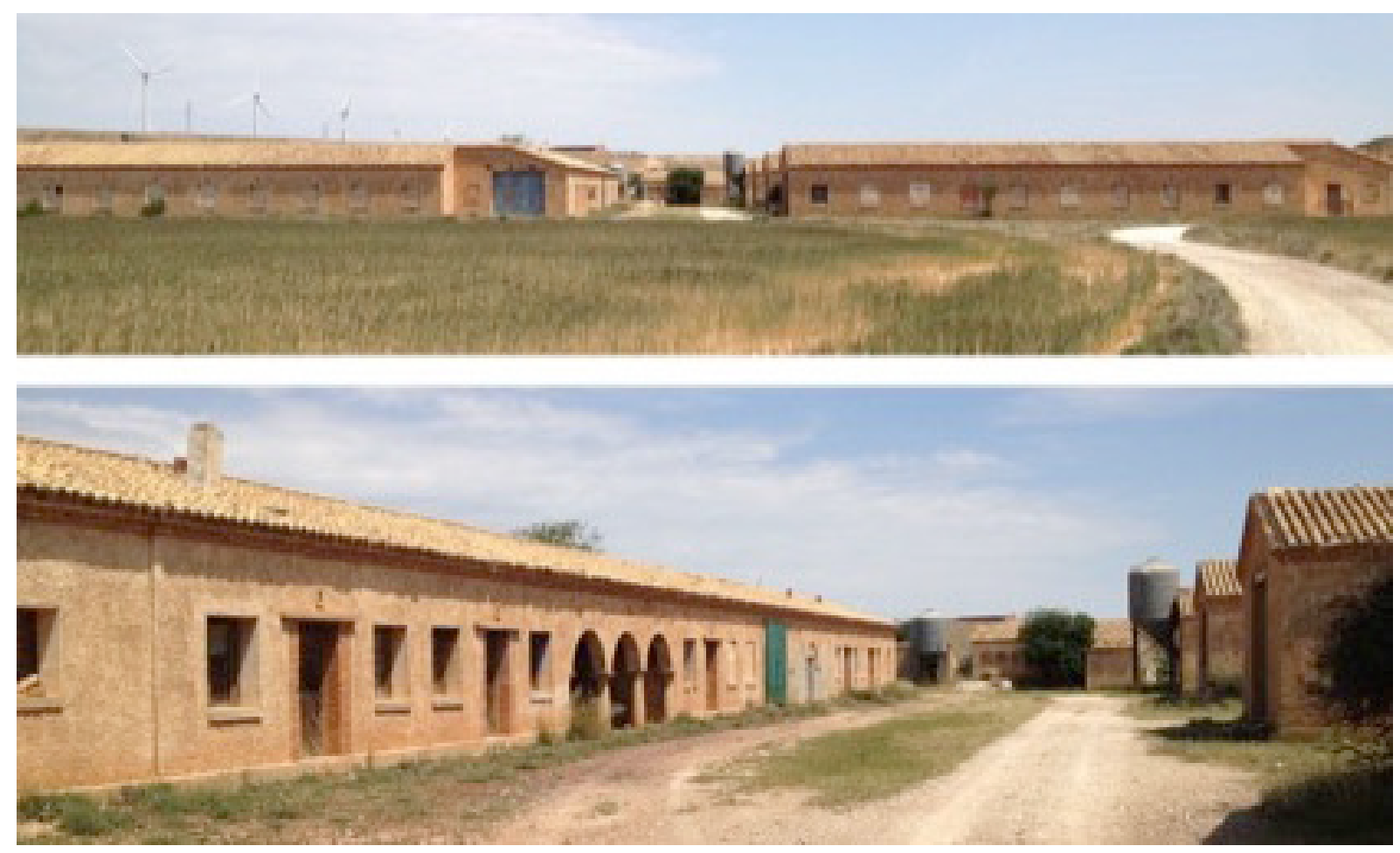

Figuras 9a y 9b. Vistas de Rusia, en Belchite, en la actualidad.

Fuentes: Fotografías del autor

94 Rodrigo 2008, p. 254. Llama especialmente la atención la reducción de presos portugueses (que pasaron de 88 a 6) y cubanos (que pasaron de 39 a 2), lo que presumiblemente deba relacionarse con las buenas relaciones del franquismo con los gobiernos de Salazar y de la órbita de Batista.

95 España Popular, 3 de febrero de 1941, p. 6.

96 Recogido en: Rodrigo 2008, p. 255.

97 AHPZ, PP, DPB, correspondencia, c. 5723/1. Oficio de 26 de mayo de 1941.

98 López Jiménez 2004, p. 89.

99 López Jiménez 2004, p. 93.

100 Orduña 1996. 
Aunque teóricamente Auxilio Social era una organización de beneficencia ${ }^{101}$, durante la guerra desempeñó un papel en los mecanismos bélicos de la retaguardia. En la posguerra, Auxilio Social fue un dispositivo para la reeducación y para la difusión de modelos familiares y de género.

Una de las aspiraciones de Auxilio Social más desconocidas es la de tener un rol en el proceso de reconstrucción nacional, sobre todo durante la guerra. La organización tenía un área de arquitectura en la que los arquitectos Lozano y Argote ${ }^{102}$ proyectaban algunas dotaciones de urgencia (como comedores o guarderías) y campamentos provisionales. Además, en su seno se constituyó la Obra del Hogar Nacional-Sindicalista ${ }^{103}$. En ese contexto se enmarca el nacimiento del quinto Belchite.

En principio para alojar a los vecinos que habían quedado sin casa, Auxilio Social decidió construir una barriada de viviendas provisionales ${ }^{104}$. El proyecto fue redactado por José María Argote en el verano de 1938, y en septiembre comenzaron las obras con el replanteo ${ }^{105}$, bajo la dirección del arquitecto José Beltrán ${ }^{106}$.

El conjunto consistía en tres peines de cuatro grandes púas cuyos pabellones podían albergar a unas 500 personas ${ }^{107}$. El grupo, de carácter utilitario pero con algunos detalles formales, contaba con un pabellón de servicios colectivos en la parte trasera y una gran explanada en la delantera en la que, como guardiana, se situaba una pequeña ermita ${ }^{108}$. Los edificios fueron proyectados para que, tras su uso provisional, sirvieran de campamento patriótico:

Este gran campamento juvenil, frente a las ruinas veneradas, será la mejor escuela de patriotismo que podemos ofrecer a las generaciones futuras ${ }^{109}$.

La obra debió de estar acabada en 1939, y en 1940 ya vivían 227 personas en 59 viviendas. El análisis de los datos disponibles, así como el registro de la memoria popular, nos permite concluir que los pabellones construidos por Auxilio Social sirvieron en su origen para alojar, fundamentalmente, a las personas izquierdistas que regresaron a Belchite después de que lo hicieran los vecinos que habían huido a la retaguardia nacionalista. Desconocemos hoy si la discriminación ideológica se hallaba en el origen del proyecto de Auxilio Social, y es posible que no, pero lo cierto es que esta nueva barriada acabó siendo un elemento indispensable para la ejecución de una política represiva mediante la que se produjo una reordenación espacial de la población en la que primó, con otros, el factor ideológico. De modo que Rusia,

101 Carasa 1997.

102 ABC (Sevilla), 25 de junio de 1937, p. 16.

103 Sánchez Blanco 2008, p. 136. Y: López Gallegos 2004, pp. 133-154.

104 AGA, Auxilio Social (en adelante AS), c. 2238, Arquitectura 1938, 1939, 1940. Actilla de la Junta de Asesores Provinciales. Y: Heraldo de Aragón, 18 de septiembre de 1938, p. 4.

105 AGA, AS, c. 2238, Arquitectura 1938, 1939, 1940, Relación de trabajos del señor Basuli. Y en la misma caja: Relación de trabajos del señor Guinea.

106 AGA, AS, c. 2238, Arquitectura 1938, 1939, 1940. Actilla de la Junta de Asesores Provinciales.

107 AGA, AS, c. 2238, Arquitectura 1938, 1939, 1940. Comunicación de septiembre de 1938 al

Departamento Central de Propaganda.

108 El conjunto figuró en: Exposición Nacional... 1939, pp. 7 y 38.

109 Heraldo de Aragón, 18 de septiembre de 1938, p. 4. 
esta Rusia de Belchite, es un espacio representativo de un tipo de represión, la de naturaleza espacial, que discrimina por motivos políticos a través de las políticas de vivienda, y que supone el arrinconamiento obligado y la reordenación espacial. Los pueblos de Regiones Devastadas son un buen ejemplo de esto último, y creemos que este tipo de represión franquista debe ser considerada junto a las represiones de otra naturaleza, como la física, la laboral o la económica ${ }^{110}$.

Los datos con que contamos en la actualidad permiten deducir lo siguiente: los habitantes de Belchite comenzaron al regresar a colocarse en sus viviendas, si existían, o en viviendas ajenas si habían perdido la suya. En este proceso intervinieron el valor que se concedía al pueblo histórico y el rechazo a un núcleo que se hallaba lejano ${ }^{111}$. Como las personas que se habían trasladado a la zona republicana (o que habían huido a Francia) tardaron más en regresar, también por miedo, cuando lo hicieron encontraron muchas de sus casas ocupadas. En ese caso, y dado que volvían a Belchite vencidos y señalados, no tenían más remedio que ocupar construcciones auxiliares o, si podían, aceptar su traslado al nuevo campo creado en la plana del río. Dada la hostilidad existente, no es posible pensar en un tipo positivo de discriminación ${ }^{112}$. Entre las familias trasladadas hubo también alguna no significada o de tendencia derechista, aunque en proporción mucho menor. La memoria popular apunta que el cabeza de una de estas últimas familias poseía la condición no oficial de alcalde de la barriada ${ }^{113}$.

El nombre de Rusia que le fue dado popularmente, denota ya de por sí su carácter heterotópico ${ }^{114}$. Una carta del Gobernador Civil al alcalde es explícita al respecto:

Visto el informe que emite esa Alcaldía en 13 del mes próximo pasado en relación con instancia producida por un vecino de esa Ciudad que al querer volver a la localidad se encuentra con que su casa está habitada por otra vecina, y en el que expone el conflicto que continuamente tiene esa Alcaldía a medida que regresan los vecinos de tendencia izquierdista por hallarse destruidos el $90 \%$ de los edificios y ser imposible devolver a aquellos sus viviendas ocupadas por los que habitan en ellas desde que se liberó la Villa, ya que en otro caso habrían estos de quedar sin albergue; signifícole que deberá V. denunciar a tales individuos de antecedentes izquierdistas ante el Tribunal de Responsabilidades Políticas a los efectos que procedan con respecto a sus bienes ${ }^{115}$.

En 1941 el ayuntamiento dejó de acometer trabajos para la instalación eléctrica para una escuela en Rusia, al considerar innecesaria la escuela "teniendo en cuenta

110 Sánchez Recio 1984, Sánchez Recio 1991, Mir et al. 1997, Álvaro 2006, Sánchez Recio 2008 y: Casanova et al. 2014.

111 AGA, AS, c. 2238, Arquitectura 1938, 1939, 1940. Copia del escrito de 23 de septiembre de 1938.

112 AMB, Correspondencia, c. 23-1, Oficio de 9 de marzo de 1939 del Gobernador Civil de Zaragoza al alcalde de Belchite.

113 El uso discriminatorio de la barriada no significa que el conjunto no cubriera una importante demanda en ese momento y que, por tanto, las viviendas no fuesen deseadas. AMB, a. 1939-1941, s. de 30 de junio de 1941, f, 75. AMB, a. 1939-1941, s. de 30 de julio de 1941, f. 79.

114 A la barriada la llamaban "la pequeña Rusia", explicaba en 1941 un brigadista internacional. España Popular, 3 de febrero de 1941, p. 6.

115 AMB, Correspondencia, c. 23-1, Oficio de 5 de octubre de 1939 del Gobernador Civil de Zaragoza al alcalde de Belchite. 
el número de familias que han pasado a ocupar las viviendas del nuevo pueblo y las que volverán a sus casas del viejo, desde aquel barrio" ${ }^{116}$. Y efectivamente muchas de las personas que abandonaron Rusia no lo hicieron para ir al pueblo nuevo sino, en primer lugar, al viejo.

La discriminación por motivos ideológicos alcanzó también al pueblo nuevo y al proceso de traslado ${ }^{117}$, y en ese sentido Rusia no representa un caso aislado sino una constante en la política de reconstrucción ${ }^{118}$, la reordenación espacial y la visibilización a través de ella de los sectores derrotados. Las políticas públicas en materia de memoria en los núcleos dañados por la guerra deben considerar las consecuencias de este "estrés habitacional" de múltiples causas, también políticas, que además conllevó una aceleración del ya de por sí acusado proceso de despoblación del medio rural. Aunque es propiedad pública, Rusia es utilizado desde hace décadas por los vecinos con fines agrícolas y ganaderos ${ }^{119}$.

\section{Belchite y la posibilidad de un lugar de memoria integrador}

Desde el punto de vista patrimonial Belchite ha planteado numerosos problemas de conservación, tanto durante el franquismo como, sobre todo, en democracia ${ }^{120}$. En esta última etapa, buena parte de ellos han surgido de la dificultad de interpretar el conjunto de los dos Belchites, concebido como monumento franquista, como un lugar de memoria inclusiva. Es prueba de ello el recelo que la atención a las ruinas del pueblo viejo ha despertado en diversos sectores, entre los que cabe citar el formado por algunos vecinos antifranquistas. Solo a partir del intento del ayuntamiento, en los años 90, por concebir el viejo Belchite como un "monumento a la paz" se logró crear el suficiente interés para que las administraciones públicas planteasen algunas inversiones.

Hasta el momento, sin embargo, no se ha considerado la posibilidad de incluir en el campo de interés de Belchite los núcleos que no son los dos que componían el "monumento" franquista ${ }^{121}$. En mi opinión, el conocimiento de los otros Belchites permite completar el discurso histórico y abrir el lugar a una memoria pública plural, inclusiva y democrática. Parece justo con la historia, y redundaría en la con-

116 AMB, a. 1939-1941, s. de 20 de diciembre de 1941, f. 95. Tampoco en 1948 se creó la escuela en Rusia. AMB, a. 1948-1950, s. de 15 de julio de 1948, f. 8.

117 Las propias normas de adjudicación de vivienda de Regiones muestran la discriminación en el reparto. AGA, RD, c. 1624, Circular 21 de febrero de 1942. Al respecto es también interesante: AHPZ, RD, c A8237, Borrador de informe de 21 de noviembre de 1963.

118 El acceso a la vivienda era más difícil y el ritmo de traslado más lento en el caso de las familias de ideologías consideradas hostiles por el régimen. En la tesis doctoral desarrollo esta cuestión y lo muestro para el caso de Belchite.

119 Auxilio Social entregó las fincas al Estado en 1970. En 1984 pasaron a la Diputación General y en 2010 fueron cedidas al ayuntamiento de Belchite (AMB, 1375-3, Expediente de cesión de bienes del conjunto de pabellones y capilla en la Plana del Río).

120 Michonneau 2011, p. 71-76.

121 Únicamente a nivel administrativo, en el marco del trámite de cesión al municipio, se ha considerado la necesidad de utilizar este conjunto para cumplir los fines de la ley popularmente denominada de memoria histórica. AMB, 1375-3, Expediente de cesión de bienes del conjunto de pabellones y capilla en la plana del río. 
servación del conjunto, que el discurso memorial eleve a la categoría de Belchites lo que fueron Belchites cuando el pueblo se convirtió en el Belchite de hoy.

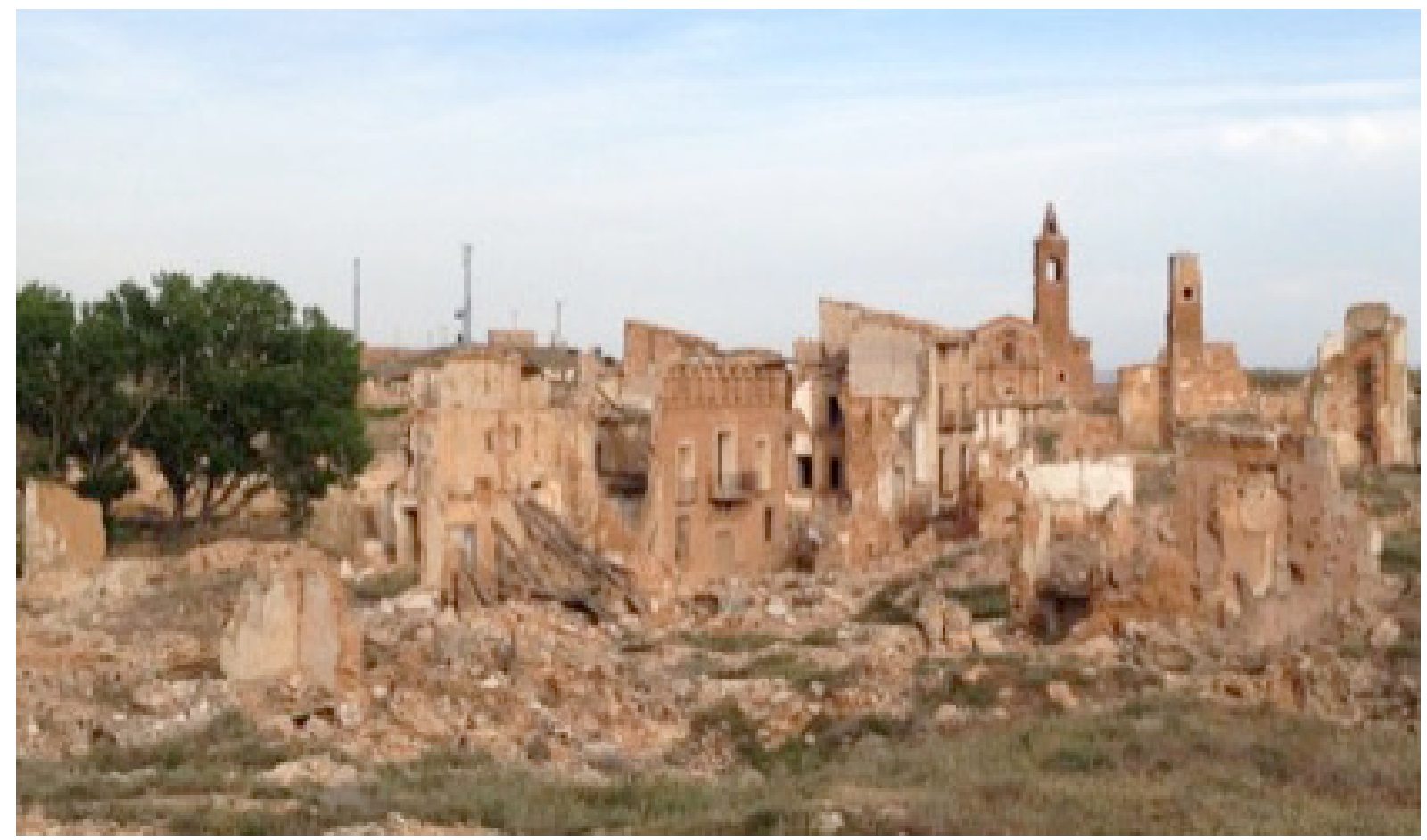

Figura 10. Vista del pueblo viejo de Belchite en 2014.

Fuente: Fotografía del autor.

De la misma manera que el símbolo de Belchite requería para su funcionamiento de solo dos pueblos, la historia y la comprensión de la sociedad franquista requieren de los cinco. Es lo que el régimen ocultó de la construcción de su símbolo, ese andamiaje heterotópico de la utopía franquista, lo que puede situar a Belchite en una posición integradora que, a su vez, es la única que puede hacer compatibles lo que parecen objetivos legítimos de las políticas públicas: que Belchite se conserve como el conjunto patrimonial que es, que la vida cotidiana de los y las habitantes pueda desarrollarse con normalidad y sin imposiciones memoriales y que los y las visitantes tengan acceso, para su libre conocimiento, a todos los lugares que explican Belchite y a las realidades que estos contienen.

\section{Bibliografía}

Ideas generales sobre el Plan Nacional de Ordenación y Reconstrucción. Madrid: Sección de Arquitectura de los Servicios Técnicos de F.E.T. y de las J.O.N.S., 1939.

Texto de las sesiones celebradas en el Teatro Español de Madrid por la Asamblea Nacional de Arquitectos los dias 26, 27, 28 y 29 de junio de 1939. Madrid: Servicios Técnicos de F.E.T. y de las J.O.N.S. (Sección de Arquitectura), 1939.

Exposición Nacional de la Vivienda Rural y de los trabajos realizados por las Fiscalías Provinciales (1. ${ }^{\circ}$ Abril 1937 a 31 Diciembre de 1938). Valiosas aportaciones de otras entidades. Valladolid: Estado Español, Ministerio de la Gobernación, Fiscalía Superior de la Vivienda, 1939. 
Segunda Asamblea Nacional de Arquitectura. Madrid: 1941.

Arquitectura en Regiones Devastadas. Madrid: Ministerio de Obras Públicas y Urbanismo, 1987.

ALLANEGUI BURRIEL, Guillermo; ARCHILLA NAVARRO, Ángel P.; CINCA YAGO, Jaime. El viejo Belchite. La agonía de un pueblo. Zaragoza: Diputación General de Aragón, 2008.

ALMARCHA NÚÑEZ-HERRADOR, Esther. Arquitectura y urbanismo rural durante el periodo de la autarquía en Castilla-La Mancha: Dirección General de Regiones Devastadas y Reparaciones e Instituto Nacional de Colonización. Cuenca: Universidad de Castilla-La Mancha, 1997.

ÁLVARO DUEÑAS, Manuel. "Por ministerio de la ley y voluntad del Caudillo": la jurisdicción especial de responsabilidades politicas (1939-1945). Madrid: Centro de Estudios Políticos y Constitucionales, 2006.

ARAGONÉS, Pablo. Alcazar de Adobes. ABC (Sevilla), 10 de octubre de 1937, pp. 3 y 4. BEAUMONT ESANDI, Edurne; MENDIOLA GONZALO, Fernando. Esclavos del franquismo en el Pirineo. La carretera Igal-Vidángoz-Roncal (1939-1941). Tafalla: Txalaparta, 2006.

BITRIÁN VAREA, Carlos. Espacio y Memoria. Habitar donde habita el recuerdo de la Guerra Civil Española. In LLORENTE DÍAZ, Marta (coord). Topología del espacio urbano. Madrid: Abada Editores, 2014.

BITRIÁN VAREA, Carlos. Villas cicatriz: los pueblos y las ruinas de la Guerra Civil española. IN GÓMEZ BRAVO, Gutmaro; PALLOL TRIGUEROS, Rubén. Congreso Posguerras. Actas del Congreso Posguerras. 75 aniversario del fin de la guerra civil española. Madrid: Editorial Pablo Iglesias, 2014, CD, p. 1-23.

BLANCO LAGE, Manuel. España Una. In Arquitectura en Regiones Devastadas. Madrid: Ministerio de Obras Públicas y Urbanismo, 1987, pp. 17-40.

BONET CORREA, Antonio (coord.). Arte del franquismo. Madrid: Cátedra, 1981.

BOX VARELA, Zira. El cuerpo de la nación. Arquitectura, urbanismo y capitalidad en el primer franquismo. Revista de estudios politicos, 2012, n. 155, pp. 151-181.

BOX VARELA, Zira. La fundación de un régimen. La construcción simbólica del franquismo. Madrid: 2008 [Edición digital de la Universidad Politécnica de Madrid: http:// eprints.ucm.es/8572/1/T30783.pdf, última consulta: 2 de enero de 2015]

BOLÍN, Luis. España. Los años vitales. Madrid: Espasa-Calpe, 1967.

BONET CORREA, Antonio (coord.). Arte del franquismo. Madrid: Cátedra, 1981.

CALVET PASCUAL, Agustí (Gaziel). La aldea de las Tullerías. La Vanguardia, 24 de junio de 1916, pp. 13-14.

CÁMARA, Antonio. Reconstrucción de Belchite. Reconstrucción, abril de 1940, n. 1, páginas 11-16.

CARASA, Pedro. La Revolución Nacional-Asistencial durante el primer franquismo (1936-1940). Historia Contemporánea, n. 16, 1997, Páginas 89-140. 
CASANOVA RUIZ, Julián; CENARRO LAGUNAS, Ángela; LANGARITA GRACIA, Estefanía; MORENO MEDINA, Nacho; MURILLO ACED, Irene. Pagar las culpas. La represión económica en Aragón (1936-1945). Madrid: Crítica y Publicaciones de Rolde de Estudios Aragoneses, 2014.

CIDÓN, Francisco de. Pueblos de Aragón devastados por la guerra. Bilbao: Huecograbado Arte, 1943.

CORREYERO RUIZ, Beatriz. Las rutas de guerra y los periodistas portugueses. Historia y Comunicación Social, 2001, n. 6, pp. 123-134.

CORREYERO RUIZ, Beatriz. La administración turística española entre 1936 y 1951. El turismo al servicio de la propaganda política. Estudios Turísticos, 2004, n. 163164, pp. 55-79.

CUERVO RADIGALES, Máximo. ¡El padre ha muerto!. Reconstrucción, abril de 1940, n. 1, p. 28.

FERNÁNDEZ FLÓREZ, Wenceslao. La «Ruta de Guerra». ABC (Sevilla), 30 de septiembre de 1938, pp. 3-6.

FORCADELL ÁLVAREZ, Carlos; SABIO ALCUTÉN, Alberto (coords). Paisajes para después de una guerra. El Aragón devastado y la reconstrucción bajo el franquismo (1936-1957). Zaragoza: Institución Fernando el Católico, 2008.

FOUCAULT, Michel. Des espaces autres (conférence au Cercle d'études architecturales, 14 mars 1967). Architecture, Mouvement, Continuité, octubre de 1984, n. 5, pp. 46-49.

FOXÁ, Agustín de. Arquitectura hermosa de las ruinas. Vértice, abril de 1937, n. 1.

FRUTOS GRACIA, Marcelino de. Belchite Inmortal (24 Agosto - 6 Septiembre 1937). Zaragoza: Imprenta del $5^{\circ}$ Grupo de Automóviles, 1944.

GÓMEZ APARICIO, Pedro. El símbolo de los dos Belchites. Reconstrucción, abril de 1940, n. 1, pp. 6-9.

GÓMEZ BRAVO, Gutmaro. La Redención de Penas. La formación del sistema penitenciario franquista, 1936-1950. Madrid: Los Libros de la Catarata, 2007.

GÓMEZ BRAVO, Gutmaro. Claves del modelo penitenciario franquista (1936-1948). Revista de Estudios Extremeños, 2011, t. LXVII, n. II, pp. 815-836.

GONZÁLEZ CORTÉS, José Ramón. Esclavizar para vencer y convencer: los Batallones de trabajadores y el trabajo forzado en el sistema represivo franquista. Revista de Estudios Extremeños, 2011 , t. LXVII, n. II, pp. 1013-1050.

GUTIÉRREZ MOLINA, José Luis. Por soñar con la libertad, los convirtieron en esclavos. Presos, prisioneros y obras públicas y privadas en Andalucía durante la guerra civil. HAOL, 2004, número 3, pp. 39-54.

GUTIÉRREZ MOLINA, José Luis. Trabajo esclavo y obras hidráulicas: extremeños en el Canal de los Presos. Revista de Estudios Extremeños, 2011, t. LXVII, n. II, pp. 973-1012.

HERNÁNDEZ MARTÍNEZ, Ascensión. La clonación arquitectónica. Madrid: Siruela, 2007. 
HOLTORF, Cornelius. Monumental Past: The Life-histories of Megalithic Monuments in Mecklenburg-Vorpommern (Germany). University of Toronto: Centre for Instructional Technology Development, 2000-2008. [en línea: http://hdl.handle. net/1807/245, última consulta: 28 de julio de 2014].

LENTZEN, Manfred. Marinetti y el futurismo en España. In NEUMEISTER, Sebastián (coord.). Actas del IX Congreso de la Asociación Internacional de Hispanistas: 18-23 agosto 1986 Berlín. Berlín: Vervuert Verlagsgesellschaft, 1989, v. 2, pp. 309-318.

LLORENTE HERNÁNDEZ, Ángel. Arte e ideología en el franquismo (1936-1951). Madrid: Visor, 1995.

LÓPEZ ARANGUREN, José Luis. La Filosofía de Eugenio d'Ors. Madrid: Ediciones y Publicaciones Españolas, 1945.

LÓPEZ DÍAZ, Jesús. Vivienda social y Falange: ideario y construcción en la década de los 40. Scripta Nova. Revista electrónica de geografía y ciencias sociales, 1 de agosto de 2003, v. VII, n. 146(024) [en línea: http://www.ub.es/geocrit/sn/sn-146(024).htm, última consulta: 2 de enero de 2015].

LÓPEZ GALLEGOS, María Silvia. La política social desarrollada por la Organización Sindical durante el primer franquismo en Zamora (1939-1945): la creación de las Obras Sindicales. Studia Zamorensia, 2004, n. 7, pp. 133-154.

LÓPEZ GÓMEZ, José Manuel. Un modelo de arquitectura y urbanismo franquista en Aragón: La Dirección General de Regiones Devastadas. 1939-1957. Zaragoza: Diputación General de Aragón, 1995.

LÓPEZ JIMÉNEZ, Francisco Javier: Fondos documentales conservados en el Archivo General Militar de Guadalajara. Cuadernos Republicanos, 2004, n. 55, pp. 85-100.

LOSADA DE LA TORRE, José (Juan de Córdoba). La reconstrucción de la España devastada por el marxismo. Guernica. $A B C$ (Sevilla), 24 de diciembre de 1937, pp. 11 y 12.

MAINER BAQUÉ, José Carlos. Falange y Literatura. Barcelona: Labor, 1971.

MARINETTI, Filippo Tommaso. Le Futurisme. Le Figaro, 20 de febrero de 1909.

MARTÍN FERNÁNDEZ, Alberto (Juan Deportista). Aquí no ha pasado nada, o cómo resurge una región. $A B C$ (Sevilla), 27 de octubre de 1937, pp. 6 y 7.

MICHONNEAU, Stéphane. Belchite: l'intention d'un lieu de mémoire victimaire ( 1937-2009). In EL KENZ, David; NÉRARD, François-Xavier (dir.). Conmmémorer les victimes en Europe. XVI ${ }^{e} X X^{e}$ siècles. Seyssel: Champ Vallon: 201 1, pp. 65-76.

MICHONNEAU, Stéphane. Ruinas de guerra e imaginario nacional bajo el franquismo. In MICHONNEAU, Stéphane; NÚÑEZ SEIXAS, Xosé M (ed.). Imaginarios y representaciones de España durante el franquismo. Madrid: Casa de Velázquez, 2014. MIR CURCÓ, Conxita; CORRETGÉ BLASI, Fabià; FARRÉ CUNILLERA, Judit; SAGUÉS SAN JOSÉ, Joan; Repressió econòmica i franquisme. L'actuació del Tribunal de Responsabilitats Polítiques a la província de Lleida. Barcelona: Publicacions de l'Abadia de Montserrat, 1997. 
MITTIG, Hans-Ernst. Dauerhaftigkeit, einst Denkmalargument. In DIERS, Michael (ed.). Mo(nu)mente: Formen und Funktionen ephemerer Denkmäler. Berlin: Akademie-Verlag, 1993, pp. 11-34.

MONTERO MORENO, Antonio. Historia de la persecución religiosa en España (19361939). Madrid: La Editorial Católica, 1961.

MUÑOZ-ROJAS, Olivia. Ashes and Granite. Destruction and Reconstruction in the Spanish Civil War and Its Aftermath. Brighton: Sussex Academic Press, 2011.

NÚÑEZ DÍAZ-BALART, Mirta. Propaganda e información en las instituciones penitenciarias del primer franquismo, 1939-1945. In Tiempo de silencio. IV Encuentro de Investigadores del franquismo, Valencia: Universidad de Valencia, 1999, pp. 674-680.

NÚÑEZ DÍAZ-BALART, Mirta. Menores para la vida, adultos para las rejas. Adolescentes en los campos de concentración franquistas. In Els camps de concentració i el món penitenciari a Espanya durant la Guerra Civil i el Franquisme, Barcelona: Museu d'Història de Catalunya-UAB/ CEFID, 2002.

ORDUÑA PRADA, Mónica. El Auxilio Social, (1936-1940). La etapa fundacional y los primeros años. Madrid: Escuela Libre Editorial, 1996.

ORLANDO. Aquello de Belchite fue algo glorioso... Hoja Oficial del Lunes, 18 de abril de 1938, p. 4.

ORS PÉREZ-PEIX, Víctor d'. Hacia la reconstrucción de las ciudades de España. Vértice, junio de 1937, número 3.

ORS PÉREZ-PEIX, Víctor d'. Confesión de un arquitecto. FE Doctrina del Estado nacionalsindicalista, número 2, 1938, páginas 207-221.

PALLARÉS, Concha; ESPINOSA DE LOS MONTEROS, José María. Miranda, mosaico de nacionalidades: franceses, británicos y alemanes. Ayer, 2005, n. 57, pp. $153-$ 187.

RODRIGO SÁNCHEZ, Javier. Reconstrucción y mano de obra reclusa en el Aragón franquista (1936-1952). In FORCADELL ÁLVAREZ, Carlos; SABIO ALCUTÉN, Alberto (coords). Paisajes para después de una guerra. El Aragón devastado y la reconstrucción bajo el franquismo (1936-1957). Zaragoza: Institución Fernando el Católico, 2008.

RODRÍGUEZ PUÉRTOLAS, Julio. Historia de la literatura fascista española. Madrid: Akal, 2008.

SAMBRICIO RIVERA-ECHEGARAY, Carlos. «...iQue coman República!»Introducción a un estudio sobre la Reconstrucción en la España de la Postguerra. Cuadernos de arquitectura y urbanismo, 1977, n. 121, pp. 21-33.

SAMBRICIO RIVERA-ECHEGARAY, Carlos. On urbanism in the early years of Francoism. In BODENSCHATZ, Harald; SASSI, Piero; WELCH GUERRA, Max. Urbanism and Dictatorship. A European Perspective. Basilea: Birkhäuser Verlag GmbH, 2015, pp. 117-134. 
SAMBRICIO RIVERA-ECHEGARAY, Carlos. The definition of New Economic Spaces in the early Francoist period. In FLOR, Pedro. Pensar História da Arte. Estudos de Homenagem a José-Augusto França. Lisboa: Esfera do Caos Editores, 2016, pp. 223247.

SÁNCHEZ DEL ARCO, Manuel ( 1 ). Un nuevo Belchite sobre las ruínas gloriosas. $A B C$ (Sevilla), 11 de mayo de 1938, p.7.

SÁNCHEZ DEL ARCO, Manuel (Justo Sevillano) (2). Un nuevo Belchite, de trazado alegre y de puro estilo aragonés, valeroso y fuerte. El Día de Palencia, 11 de mayo de 1938, portada.

SÁNCHEZ-BIOSCA, Vicente. Hermosas, acusadoras, ruinas. Lars. Cultura y ciudad, 2007, n. 9.

SÁNCHEZ-BIOSCA, Vicente. Arquitectura, lugar de memoria y mito. El Alcázar de Toledo o la imagen prendida. In CASAR PINAZO, José Ignacio; ESTEBAN CHAPAPRÍA, Julián (eds.). Bajo el signo de la victoria. La conservación del patrimonio durante el primer franquismo (1936-1958). Valencia: Pentagraf Editorial, 2008, pp 71-83.

SÁNCHEZ BLANCO, Laura. Auxilio Social y la educación de los pobres: del franquismo a la democracia. Foro de Educación, 2008, n. 10, pp. 133-166.

SÁNCHEZ RECIO, Glicerio. Las responsabilidades Politicas en la postguerra española. El partido judicial de Monóvar. Alicante: Universidad de Alicante, 1984.

SÁNCHEZ RECIO, Glicerio. La República contra los rebeldes y los desafectos. La represión económica durante la guerra civil. Alicante: Universidad de Alicante, 1991.

SÁNCHEZ RECIO, Glicerio. La Caja General de Reparaciones y la represión económica en la República. In FUENTES QUINTANA, Enrique; COMÍN COMÍN, Francisco (coords.). Economía y economistas españoles en la guerra civil. Barcelona: Galaxia Gutenberg y Real Academia de Ciencias Políticas y Morales, 2008, pp. 939-981.

THOMAS, Hugh. La Guerra Civil Española. Barcelona: Random House Mondadori, 2004 [1976].

TEIRA CUBEL, Félix. Ruinas al Sol. Rolde, Revista de Cultura Aragonesa, abril-junio de 2006, n. 116, pp. 42-45.

TEIRA CUBEL, Félix. Belchite y la línea del Ebro. In FORCADELL ÁLVAREZ, Carlos; SABIO ALCUTÉN, Alberto (coords). Paisajes para después de una guerra. El Aragón devastado y la reconstrucción bajo el franquismo (1936-1957). Zaragoza: Institución Fernando el Católico, 2008.

TRABAL SAUS, José Antonio. La República tiene su ejército. La Vanguardia, 26 de diciembre de 1937.

UREÑA, Gabriel. Arquitectura y Urbanística civil y militar en el periodo de la autarquía (1936-1945). Madrid: Istmo, 1979. 
VÁZQUEZ ASTORGA, Mónica. Belchite: un nuevo pueblo nacido a la sombra de unas gloriosas ruinas. In CINCA YAGO, Jaime; ONA GONZÁLEZ, José Luis (coords.). Comarca de Campo de Belchite. Zaragoza: Diputación General de Aragón, 2010, pp. 24l-248.

VIEJO-ROSE, Dacia. Reconstructing Spain: cultural heritage and memory after Civil War. Brighton: Sussex Academic Press, 2011.

(c) Copyright: Carlos Bitrian Varea, 2017

(c) Copyright Scripta Nova, 2017.

Ficha bibliográfica:

BITRIAN VAREA, Carlos. Los cinco Belchites. Utopías y heterotopías enb el prierm Franquismo. Scripta Nova. Revista Electrónica de Geografía y Ciencias Sociales. [En línea]. Barcelona: Universidad de Barcelona, 15 de octubre de 2017, vol. XXI, nº 576. 